\title{
Saccharomyces cerevisiae immobilized onto cross- linked chitosan beads: application of a novel material for the removal of dye toxicity
}

\section{Guilherme Dilarri \& Carlos Renato Corso}

To cite this article: Guilherme Dilarri \& Carlos Renato Corso (2018) Saccharomyces cerevisiae immobilized onto cross-linked chitosan beads: application of a novel material for the removal of dye toxicity, Environmental Technology, 39:14, 1851-1867, DOI: 10.1080/09593330.2017.1340351

To link to this article: https://doi.org/10.1080/09593330.2017.1340351

Accepted author version posted online: 08

Jun 2017.

Published online: 20 Jun 2017.

Submit your article to this journal $\pi$

Џ Article views: 77

View Crossmark data $\complement$

Citing articles: 1 View citing articles $\lceil\nearrow$ 


\title{
Saccharomyces cerevisiae immobilized onto cross-linked chitosan beads: application of a novel material for the removal of dye toxicity
}

\author{
Guilherme Dilarri (1) and Carlos Renato Corso \\ Department of Biochemistry and Microbiology, São Paulo State University, Rio Claro, Brazil
}

ABSTRACT

Waste from textile industries can severely harm the environment. Dyes are the main residues of these effluents. Saccharomyces cerevisiae is already known to be an efficient adsorbent for the removal of dyes. However, the lack of applicability and limitation of the use of cell biomass in an industrial treatment makes it impossible to apply them. Thus the aim of this work was to immobilize S. cerevisiae in cross-linked chitosan beads by two different techniques (contact immobilization and encapsulation in the polymer matrix), proposing two new materials for adsorption. Adsorption experiments were carried out to analyse the kinetics, isotherm and thermodynamics adsorptive of the synthesized materials. The adsorption data obtained were compared with the $S$. cerevisiae biomass and with the cell-free cross-linked chitosan beads to evaluate the efficiency of the two synthesized materials. The Fourier transform infrared spectrophotometer was used to characterize and analyse the main adsorption sites of the tested materials. Bioassays using the microcrustacean Daphnia similis verified if the materials could reduce the toxicity of the medium after its application in the treatment. Both materials synthesized in this work can potentially remove dyes from effluents, in addition to being able to significantly decrease dye toxicity from an aqueous medium.
ARTICLE HISTORY

Received 1 April 2017

Accepted 2 June 2017

KEYWORDS

Adsorption; bioassays;

biopolymer; bioremediation;

textile industries; yeast

\section{Introduction}

The textile industry is an important socioeconomic segment in many countries, but is responsible for the production of large volumes of effluents that contain synthetic dyes. Once discarded in the environment, these dyes prevent the penetration of sunlight into water, thereby altering photosynthetic activity and decreasing the solubility of oxygen, with consequent harm to the entire aquatic system [1]. Moreover, dyes and derivatives can be highly toxic, exerting mutagenic and carcinogenic effects on organisms [2].

One of the alternatives to avoid such environmental impacts is to treat these effluents before they are discharged into the bodies of water. The techniques of flocculation, ozonation and photodegradation have been employed to treat effluents contaminated with dyes [3], but the high costs of chemical methods renders use unviable. Biological treatments constitute another alternative, in which microorganisms are used to degrade dyes [1], but such methods often depend on a large area for application and require a prolonged period of time to complete the treatment process. In contrast, adsorption is an efficient technique for treating dyes in textile effluents, since this method does not require a large physical area of application and offers a short treatment time. Adsorption is also a low-cost method in which several materials can be used as adsorbent agents [4]. A large number of different products have been employed as adsorbent material, such as coal coke, bentonite, resin, cotton, sand, rice hulls, palm tree straw, steel slag, feathers, steel waste, tannery waste and the seed husks from Araucaria sp. [5]. However, activated carbon remains the most used material in adsorption processes [4]. Due to the costs and high demand of materials, it is increasingly necessary to search for novel, efficient, low-cost adsorbent materials.

Chitosan is a biopolymer obtained through the deacetylation of chitin from the exoskeleton of arthropods or fungal cell walls that has been widely employed as an adsorbent in the removal of dyes [6]. Fishing for shrimp and other economically important arthropods has become an environmental problem due to the disposal of shells and other waste products that are discarded as part of fishing rubbish. Thus, the use of chitin and chitosan offers a better destination for these waste products, enabling the acquirement of a biopolymer material from a practically inexhaustible source. Another advantage of using chitosan is the ability to synthesize materials with different properties and applications. Several studies 
have reported modified forms of chitosan, such as chitosan flakes, microspheres, nanoparticles, biofilms, crosslinked chitosan and chitosan with a high rate of deacetylation [7].

The yeast Saccharomyces cerevisiae is employed in different industrial and biotechnological processes and is the most widely used eukaryotic microorganism in the world. From the industrial point of view, S. cerevisiae is one of the most common biocatalysts and biomass of this yeast is produced on a large scale [8]. S. cerevisiae has applications in the food industry, sugar-ethanol plants, pharmaceutical industry, effluent bioremediation, genetic modification and biotechnology. Moreover, this microorganism is inexpensive, safe, easily grown and readily available [3]. In Brazil, the biomass of $S$. cerevisiae is a by-product of alcoholic fermentation processes and is often discarded or redirected to other processes by sugar-ethanol plants.

The potential use of $S$. cerevisiae in the bioremediation of textile dyes has been reported in previous studies [9], but yeast cells have several disadvantages when suspended, such as low density, low mechanical resistance and low stiffness [10]. Another problem is the solidliquid separation [11], which is achieved through filtration, centrifugation or high pressure, rendering use on an industrial scale unviable. Cell immobilization constitutes a solution to this problem, offering the advantages of easy solid-liquid separation, the possibility of the reuse of the material, control of the characteristics of the material, such as size and rigidity and greater practicality in continuous flow systems [12].

The aim of the present study was to synthesize crosslinked chitosan beads and perform two different types of immobilization of $S$. cerevisiae cells on this biopolymer material, developing a novel material for application as an adsorbent of textile dyes. For the comparison of the adsorbent capacity, the cell-free cross-linked chitosan beads and yeast biomass was tested against the other materials synthetized in this work. The textile dye Direct Orange 2GL was used as the adsorbate and bench tests were performed for the determination of the kinetics, isotherm and thermodynamics of each material tested. Fourier transform infrared (FT-IR) spectrophotometric analyses were performed before and after adsorption to identify the sorption type and the main sites of adsorbate/adsorbent interaction of each material. Bioassays were also performed with the microcrustacean Daphnia similis to determine the toxicity of the dye solution before and after treatment with each of the materials, thereby testing the ability of the adsorbents to remove both colour and toxicity from the solution.

\section{Materials and methods}

\subsection{Direct orange $2 \mathrm{GL}$}

The dye used in this study was Direct Orange 2GL (DO $2 \mathrm{GL}$ ), which belongs to the group of sulphonated reactive azo dyes (Chemical Abstract Service: 1325-54-8), and was obtained from the Dimacolor Industry Group Co. This dye has an empirical formula of $\mathrm{C}_{12} \mathrm{H}_{10} \mathrm{~N}_{3} \mathrm{NaO}_{3} \mathrm{~S}$, molecular weight of $299 \mathrm{~g} \mathrm{~mol}^{-1}, 70 \%$ degree of purity, $\mathrm{pH} 6.00$ and $\lambda \max =415.608$. DO $2 \mathrm{GL}$ is water soluble and stable at wide $\mathrm{pH}$ range. The stock solution of the dye was prepared by dissolving $2000 \mathrm{mg}$ of the dye powder in $2 \mathrm{~L}$ of deionized water. The solution was then placed in an amber glass and stored at room temperature.

\subsection{Chitosan}

Chitosan was obtained from Purifarma Chemistry \& Pharmaceutical Ltda. - Brazil and was derived from crustacean skeleton chitin, with $5.60 \times 10^{-3} \mathrm{~mol}$ of amino groups per gram of biopolymer, $90 \%$ degree of deacetylation, 80 mesh grain size, $\mathrm{pH} 7.50$ and density of $0.38 \mathrm{~g} \mathrm{~mL}^{-1}$. The chitosan used in this study have a point of zero charge $\left(\mathrm{pH}_{\mathrm{pzc}}\right)$ at $\mathrm{pH} 6.30$ as described by Toledo et al. [13].

To prepare the cross-linked chitosan beads, $1 \mathrm{~g}$ of the chitosan powder was dissolved in $35 \mathrm{~mL}$ of a $5 \%\left(\mathrm{~m} \mathrm{v}^{-1}\right)$ glacial acetic acid $\left(\mathrm{C}_{3} \mathrm{COOH}\right)$ solution. The viscous solution formed was placed on a magnetic stirrer for $16 \mathrm{~h}$ until homogeneous. The solution was then dripped through a $20-\mathrm{mL}$ Burette into $200 \mathrm{~mL}$ of sodium hydroxide $(\mathrm{NaOH}) 2.50 \mathrm{~mol}$ and shaken with the aid of the magnetic stirrer, forming the cross-linked chitosan beads. After separation from the $\mathrm{NaOH}$ solution by filtration, the beads were washed with deionized water $(\mathrm{pH} 7.00)$ and dried at $323.15 \mathrm{~K}$ for $24 \mathrm{~h}$ to achieve the xerogel. The mean diameter of the beads was measured using the technique described by Dias et al. [14] with the aid of callipers and a stereoscopic microscope. The diameter of 50 beads was measured and the average was determined.

\subsection{S. cerevisiae}

A stock suspension was prepared by diluting $100 \mathrm{~g}$ of freeze-dried S. cerevisiae in $1 \mathrm{~L}$ of $0.85 \%$ saline solution (pH 6.80) for a total concentration of $10 \%$. A standard was prepared with dilutions from $0.1 \%$ to $1.0 \%$ of this stock suspension. Absorbance analysis was performed with a UV-VIS spectrophotometer (Shimadzu Model 2401-PC) at $540 \mathrm{~nm}$ [15] to determine the exact values of yeast concentration in the samples. 


\subsection{Immobilization of cells by contact (ICC)}

Ten grams of cross-linked chitosan beads were added to a $250-\mathrm{mL}$ Erlenmeyer flask containing $100 \mathrm{~mL}$ of $1 \%$ stock S. cerevisiae suspension. The solution was placed under constant agitation at $150 \mathrm{rpm}$ for $24 \mathrm{~h}$ at $301.15 \mathrm{~K}$. The beads were then separated from the liquid medium and an aliquot of the solution was collected for UV-VIS spectrophotometer analysis. Equation (1) was used to determine the percentage of cells immobilized onto the cross-linked chitosan beads by contact (ICC).

$$
\operatorname{Im}(\%)=\frac{[A b i-(A b f-A b w)] \cdot 100}{A b i}
$$

in which $\operatorname{Im}(\%)$ is the percentage of immobilized cells, $A b i$ is absorbance of the initial yeast solution, $A b w$ is absorbance of the control sample containing only deionized water after contact with beads and $A b f$ is absorbance of the final yeast solution after contact with the beads.

\subsection{Encapsulation of cells matrix (ECM) in cross- linked chitosan beads}

To immobilize the yeast cells in the polymer matrix of the ECM cross-linked chitosan beads, $100 \mathrm{~mL}$ of $10 \%$ stock suspension of $S$. cerevisiae were placed in a 500-mL Erlenmeyer flask, followed by the addition of $5 \mathrm{~mL}$ of glacial acetic acid $\left(\mathrm{C}_{3} \mathrm{COOH}\right)$ with $2.85 \mathrm{~g}$ of chitosan powder. This solution remained under magnetic stirring for $16 \mathrm{~h}$. The solution formed was then dripped through a 20-mL Burette into $500 \mathrm{~mL}$ of sodium tripolyphosphate $\left(\mathrm{Na}_{5} \mathrm{O}_{10} \mathrm{P}_{3}\right) \quad 10 \%\left(\mathrm{~m} \mathrm{v}^{-1}\right)$ on the magnetic stirrer. The formed beads were separated and washed with deionized water $(\mathrm{pH} 7.00)$ and dried at $303.15 \mathrm{~K}$ for $24 \mathrm{~h}$.

\subsection{Adsorption kinetics}

For the kinetic study, $20 \mathrm{~mL}$ of DO $2 \mathrm{GL}$ dye solution were placed in 50-mL Erlenmeyer flasks at a concentration of $100 \mu \mathrm{gL}^{-1}$ and $\mathrm{pH} 2.50$. Fifty milligrams of dry mass of each adsorbent material tested in this work remained in contact with the dye solution for $5 \mathrm{~h}$ at a temperature of $303.15 \mathrm{~K}$ and constant agitation at $40 \mathrm{rpm}$. The sample was analysed in a UV-VIS spectrophotometer every $30 \mathrm{~min}$, with scanning from 200 to $800 \mathrm{~nm}$ in a quartz cuvette measuring $10 \mathrm{~mm}$ in width. The supernatant was centrifuged for $20 \mathrm{~min}$ at $4000 \mathrm{rpm}$ before each analysis. The dye adsorbed was calculated using Equation (2).

$$
q e=\frac{V \cdot(\mathrm{Co}-\mathrm{Ce})}{W}
$$

in which $W$ is the mass of adsorbent (mg), Co and Ce are the initial and equilibrium concentrations of adsorbate solution ( $\left.\mu \mathrm{g} \mathrm{mL}^{-1}\right), V$ is volume $(\mathrm{mL})$ and $q e$ is the equilibrium adsorbate concentration on the adsorbent $\left(\mu \mathrm{g} \mathrm{m}{ }^{-1}\right)$.

\subsection{Isotherms and thermodynamic studies}

Isotherms and thermodynamics studies were performed using $20 \mathrm{~mL}$ of the dye solution at a concentration of $100 \mathrm{\mu g} \mathrm{mL}^{-1}$ in 50-mL Erlenmeyer flasks. The adsorbents remained in contact with the dye solution for $5 \mathrm{~h}$ before analysis in the UV-VIS spectrophotometer.

The isotherm studies were performed with the dye solution in a range of $\mathrm{pH}$ values (2.50, 4.50, 6.50 and 8.50), with a constant temperature of $303.15 \mathrm{~K}$ and agitation at $40 \mathrm{rpm}$. The dry weight of the adsorbents ranged from 20 to $60 \mathrm{mg}$. Adsorption studies varying the $\mathrm{pH}$ of solutions tend to choose a variation range of $(2.00,4.00,6.00$ and 8.00 ), and may have variations even beyond the ones in our study [16,17]. However, a toxicity study using the microcrustaceans $D$. similis in this work at the chosen range of $\mathrm{pH}$ variation was strategic, since the microcrustaceans only tolerate solutions ranging from $\mathrm{pH} 6.50$ to 7.50 [18]. Another important fact of the choice of this $\mathrm{pH}$ range used in this study was due to Brazilian regulations where an effluent can only be discarded if the $\mathrm{pH}$ of the solution is between 6.50 and 8.50 [19], the same $\mathrm{pH}$ range being addressed in this study.

For the thermodynamic studies, the temperature ranged from 283.15 to $323.15 \mathrm{~K}$ at $\mathrm{pH} 2.50$, in constant agitation of $40 \mathrm{rpm}$ and the dry weight of adsorbent materials was $50 \mathrm{mg}$.

All kinetic, isotherm and thermodynamic studies were conducted in triplicate and the mathematical models that adequately fit to data were confirmed by standard deviation (SD) values (Equation (3)).

$$
\mathrm{SD}=\sqrt{\frac{1}{N-1} \sum_{i=1}^{N}\left(\frac{\text { Qie - Qic }}{\text { Qie }}\right)^{2}}
$$

in which Qie and Qic $\left(\mu \mathrm{g} \mathrm{mg}^{-1}\right)$ are experimental and calculated mass of dye adsorbed by the adsorbent materials and $N$ is the number of measurements.

\subsection{FT-IR spectrophotometry}

The dye and the adsorbent materials were analysed before and after adsorption using an FT-IR spectrophotometer (Shimadzu Model 8300). The samples were heated at $378.15 \mathrm{~K}$ for $24 \mathrm{~h}$ in an incubator. Salt pellets were prepared using $149 \mathrm{mg}$ of $\mathrm{KBr}$ and $1 \mathrm{mg}$ of dry samples, which were homogenized and compressed at $40 \mathrm{kN}$ for $5 \mathrm{~min}$. The pellets were placed in the sample holder in the FT-IR spectrophotometer and absorbance 
was analysed over a range of $400-4000 \mathrm{~cm}^{-1}$ with 32 scans at a resolution of $4 \mathrm{~cm}^{-1}$. The graphs, chemical structure figures and mathematical calculations were made with the aid of the following software programs: Origin 6.10 and ACD/ChemSketch - Freeware.

\subsection{Toxicity test with microcrustacean D. similis}

The microcrustacean $D$. similis used in the experiment was from cultures kept at the Laboratory of Education and Research of Water Toxicity of the Department of Biochemistry and Microbiology of São Paulo State University (UNESP), Rio Claro, Brazil. The test organisms were kept in 1-L beaker containing $800 \mathrm{~mL}$ of maintenance water at $\mathrm{pH} 6.50$ in a temperature-controlled incubator of $293.15 \mathrm{~K}$, illumination of $1000 \mathrm{Lux}$ and photoperiod $16 \mathrm{~h}$ of light and $8 \mathrm{~h}$ of darkness. Feeding was performed daily with a 2-mL suspension of the microalga Pseudokirchneriella subcapitata at a concentration of 3.00$3.50 \times 10^{7} \mathrm{~mL}$ (determined by microscopic counting in a Petroff-Hausser chamber) and $1 \mathrm{mg}$ of fish feed. The maintenance water was renewed twice a week.

Toxicity tests were conducted following the method described by Corso and Almeida [18], in which the lethal concentrations $\left(\mathrm{LC}_{50}\right)$ and $\left(\mathrm{LC}_{100}\right)$ were determined using the Trimmed Spearman-Karber method. The microcrustaceans were submitted to the different solutions containing DO $2 \mathrm{GL}$ dye in a static system and the mortality rate of $D$. similis was determined after $48 \mathrm{~h}$ of contact. A dye-free sample and one with a known sodium dodecyl sulphate $\left(\mathrm{NaC}_{12} \mathrm{H}_{25} \mathrm{SO}_{4}\right)$ concentration were used as controls.

To test the toxicity of the solution after the adsorption process, $100 \mathrm{~mL}$ of a dye solution having the same concentration as the $\mathrm{LC}_{50}$ at $\mathrm{pH} 6.50$ were used at a temperature of $293.15 \mathrm{~K}$. A total of 100, 250 and $500 \mathrm{mg}$ of the adsorbent materials were used. During adsorption, the solution was under constant agitation at $40 \mathrm{rpm}$. After $5 \mathrm{~h}$ contact, the adsorbents were separated from the solutions and D. similis was placed in contact with the solutions for $48 \mathrm{~h}$ without agitation. The number of living organisms was then counted. The tests were performed with four replicates and were submitted to non-parametric statistical analyses using the Kruskal-Wallis method with the aid of the BioEstat 4 program, which is the most suitable analysis for comparative bioassays [20].

\section{Results and discussion}

\subsection{Synthesized materials}

The cross-linked chitosan beads synthesized in this work exhibited similar characteristics in terms of resistance, colour, shape and size (Figure 1). Some were not perfectly spherical, but rather oval. Naturally, not all chitosan beads come out perfect during synthesis due to the complexation that the chitosan gel undergoes when dripped into a strong base, with the possibility of deformity upon contact with the solution [14].

The beads involved in the process of $S$. cerevisiae immobilization by contact had the same physical characteristics as the spheres without cells, with no visual changes. A total of $17.62 \%$ of cells were immobilized with this method. The beads that had the yeast cells immobilized on their polymer matrix exhibited a slightly more yellowish colour, this being their only distinction.

\subsection{Adsorption kinetics}

The kinetic studies demonstrated that the ECM crosslinked chitosan beads reached adsorption equilibrium faster than the other adsorbents and also had the highest $q e_{(\exp )}$ value, indicating that this is the material with highest sorption capacity (Figure 2). Moreover, the cross-linked chitosan beads had the lowest $q e_{(\exp )}$, besides taking longer to reach the equilibrium time when compared to other adsorbents. This is indicative that the immobilization of cells on the chitosan beads is efficient at increasing sorption capacity.

To determine and interpret the kinetic data, the mathematical models pseudo-first order [21] (Equation (4)) and pseudo-second order [22] (Equation (5)) were employed.

$$
\ln (q e-q t)=\ln q e-k 1 \cdot t
$$

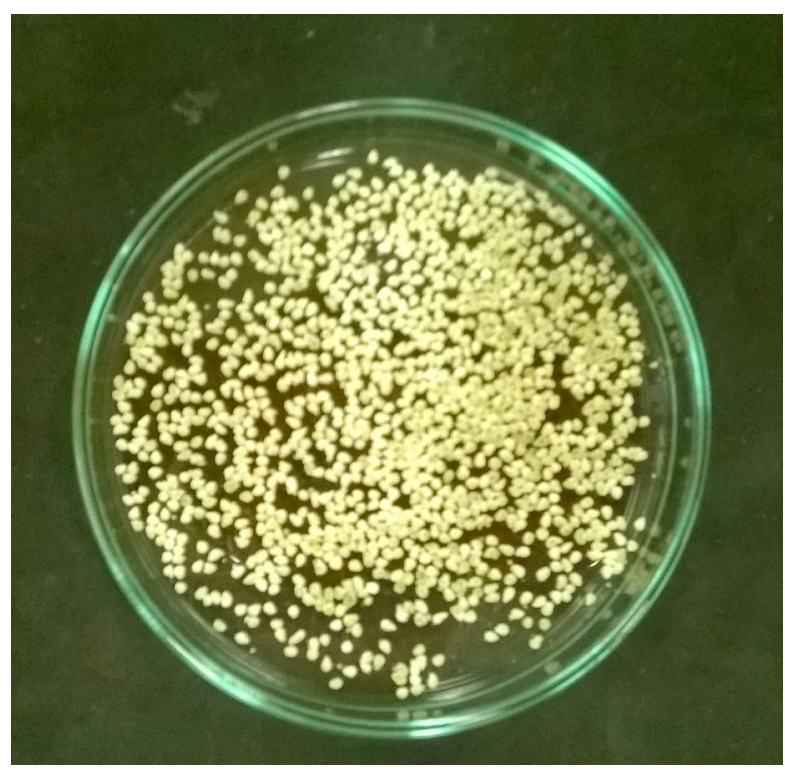

Figure 1. Cross-linked chitosan beads in the form of xerogel: spherical and oval shapes with diameter of $0.15 \mathrm{~cm}$. 


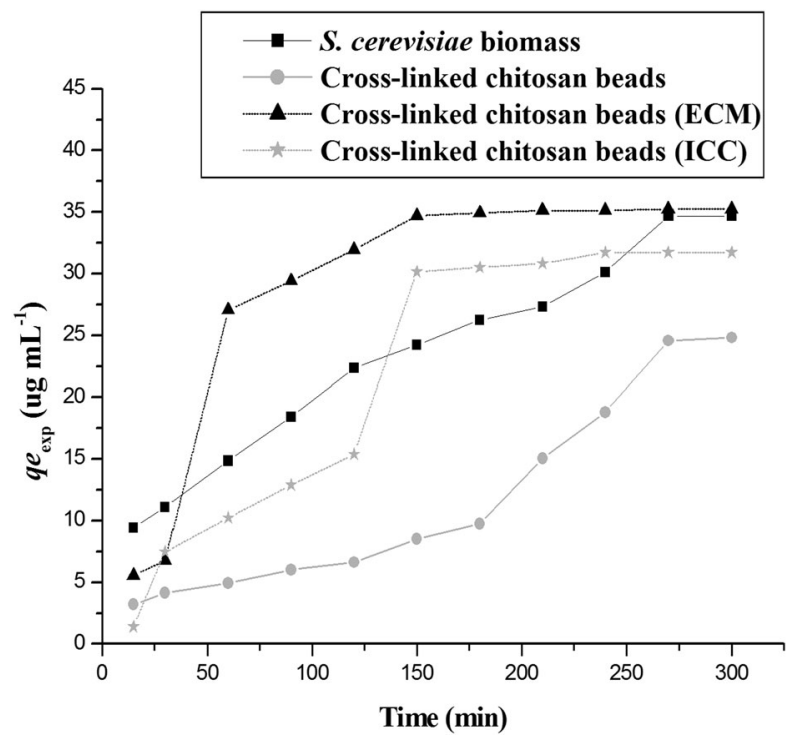

Figure 2. Experimental adsorptions kinetics of all materials tested (DO 2GL concentration of $100 \mu \mathrm{g} \mathrm{mL}^{-1}, \mathrm{pH} 2.50,40 \mathrm{rpm}$ of constant agitation, $50 \mathrm{mg}$ of dry mass adsorbents and 300 min of contact).

$$
\frac{t}{q t}=\frac{1}{k 2 \cdot q e^{2}}+\frac{1}{q e} \cdot t
$$

in which $t$ is time (min), qt is the amount of dye sorbed at time $t\left(\mu \mathrm{g} \mathrm{mg}^{-1}\right), k 1$ is the pseudo-first order rate constant $\left(\mathrm{min}^{-1}\right)$ and $k 2$ is the pseudo-second order rate constant (mg $\mathrm{mg}^{-1} \mathrm{~min}^{-1}$ ).

To find the values of the constants $k 1, k 2$ and $q e_{\text {(cal) }}$ (Table 1), linear regression was made of the pseudofirst order plot graphs $(\ln (q e-q t)$ vs. $t)$ and pseudosecond order plot (t/qt vs. $t$ ).

All adsorbent materials tested better fit the pseudosecond order model, with a correlation coefficient greater than the pseudo-first order model. The $q e_{\text {(cal) }}$ values obtained in the pseudo-second order model were also closer to the $q e_{(\exp )}$, confirming the better fit to the model (Table 1). This result is indicative of the occurrence of chemisorption, since the pseudo-second order model assumes that adsorption is controlled by processes of chemical interactions [23].

It is possible that the dye penetrates into the layers of the adsorbent materials, with the occurrence of adsorption beyond the external surface, which is denominated intraparticle diffusion. Through the mathematical model proposed by Weber and Morris [24] (Equation (6)), the graph of $q t$ vs. $t^{0.5}$ was plotted (Figure 3) to determine whether such a phenomenon was indeed occurring.

$$
q t=K d i \cdot t^{0.5}+C
$$

in which $C$ is a constant related to the thickness of the diffusion layers ( $\mu \mathrm{g} \mathrm{mg}^{-1}$ ) and $K d i$ is the constant intraparticle diffusion rate $\left(\mathrm{mg}^{\mathrm{m}} \mathrm{g}^{-1}\left(\mathrm{~min}^{0.5}\right)^{-1}\right)$.

The two linear regions formed in the four graphs confirm the occurrence of intraparticle diffusion in all materials tested. These two lines represent the boundary layer followed by intraparticle diffusion in macro and meso pores [22]. Moreover, all four materials only reached sorption equilibrium when the dye entered the meso pore layer.

The yeast biomass and the ICC and ECM cross-linked chitosan beads had higher Kdi values in the macro pore layer than the meso pore layer (Figure 3), indicating that the dye is first adsorbed on the surface, followed by intraparticle diffusion. In contrast, cross-linked chitosan beads had lower Kdi values in the macro pore layer (Figure 3), demonstrating that the first boundary layer offers no resistance to intraparticle diffusion, which occurs very rapidly in these beads [25]. Chitosan beads usually have pores throughout the surface [14] that facilitate the penetration of the liquids into the spheres and consequently facilitate the occurrence of intraparticle diffusion [26]. The cells immobilized on the material likely slowed the penetration of the dye in the pores and the internal portion of the chitosan beads, forming a more resistant layer to diffusion, which would explain the difference in the ICC and ECM cross-linked chitosan beads.

Through the kinetic expression proposed by Boyd et al. [27] (Equation (7)), it is possible to predict the actual slow step involved in intraparticle diffusion [28].

$$
B t=-0.4977-\ln \left(1-\frac{q t}{q e}\right)
$$

in which $B t$ is a mathematical function of $q t / q e$ at any

\begin{tabular}{|c|c|c|c|c|c|c|c|c|c|}
\hline \multirow[b]{2}{*}{ Adsorbents materials } & \multirow[b]{2}{*}{$\begin{array}{c}q e_{(\exp )} \\
\left(\mu \mathrm{gg}^{-1}\right)\end{array}$} & \multicolumn{4}{|c|}{ Pseudo-first order } & \multicolumn{4}{|c|}{ Pseudo-second order } \\
\hline & & $k 1\left(\min ^{-1}\right)$ & $\begin{array}{c}q e_{(\mathrm{cal})} \\
\left(\mu \mathrm{g} \mathrm{m}^{-1}\right)\end{array}$ & $R^{2}$ & SD & $\begin{array}{c}k 2\left(\mathrm{mg} \mu \mathrm{g}^{-1}\right. \\
\left.\min ^{-1}\right)\end{array}$ & $\begin{array}{c}q e_{(\text {cal })} \\
\left(\mu \mathrm{gg}^{-1}\right)\end{array}$ & $R^{2}$ & SD \\
\hline S. cerevisiae biomass & 34.664 & 0.0072 & 38.592 & 0.859 & 3.675 & 0.0038 & 29.763 & 0.991 & 0.079 \\
\hline Cross-linked chitosan beads & 24.791 & 0.0046 & 11.870 & 0.880 & 0.214 & 0.0012 & 26.838 & 0.937 & 1.870 \\
\hline $\begin{array}{l}\text { Cross-linked chitosan beads } \\
\text { (ECM) }\end{array}$ & 35.235 & 0.0276 & 43.802 & 0.986 & 0.222 & 0.0011 & 38.461 & 0.998 & 0.118 \\
\hline Cross-linked chitosan beads (ICC) & 31.715 & 0.0199 & 41.499 & 0.923 & 0.632 & 0.0050 & 35.963 & 0.942 & 0.839 \\
\hline
\end{tabular}
time $t$.

Table 1. Comparison of kinetic parameters obtained. 

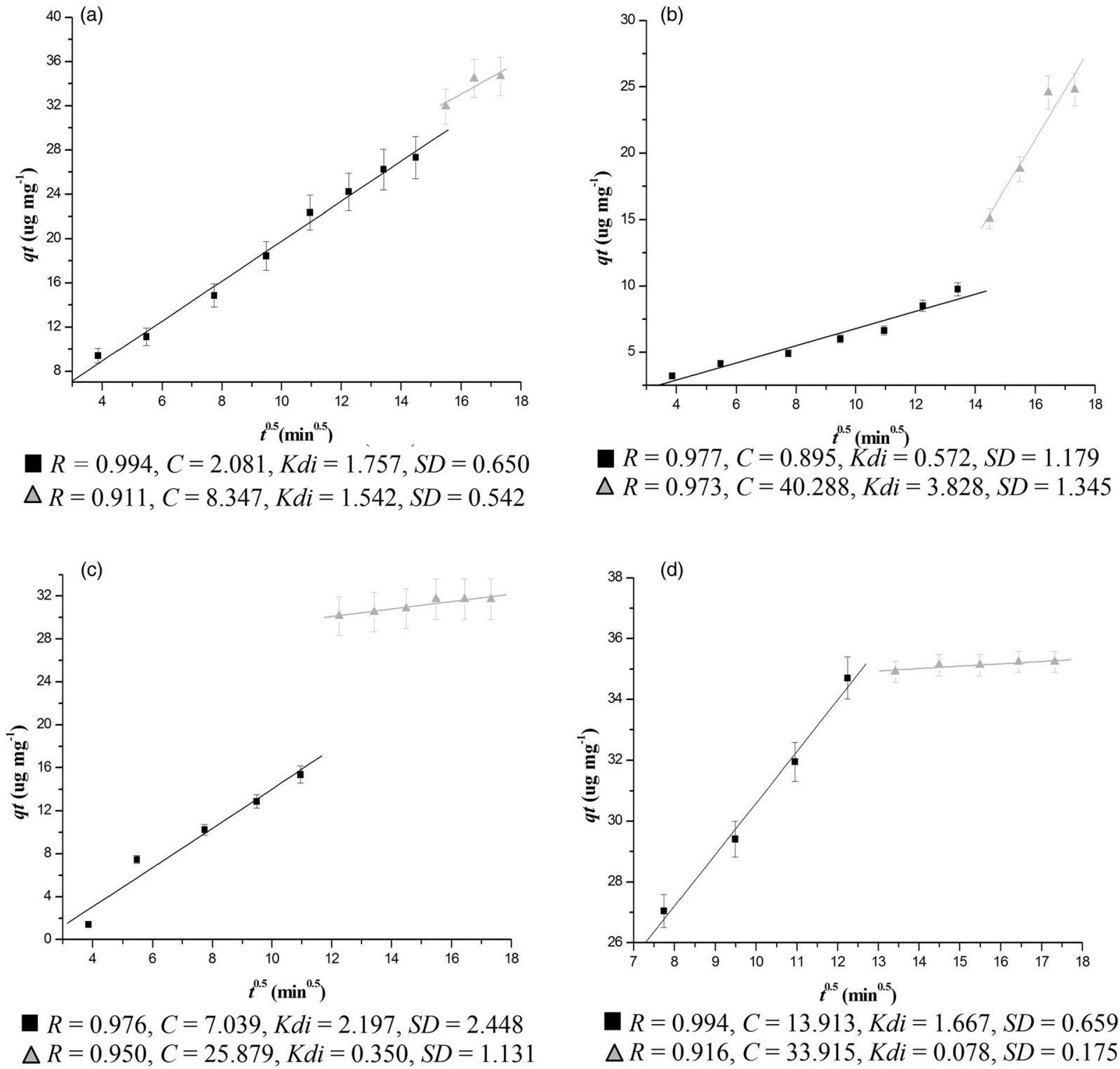

Figure 3. Intraparticle diffusion of all materials ((a) S. cerevisiae biomass, (b) cross-linked chitosan beads, (c) ICC cross-linked chitosan beads and (d) ECM cross-linked chitosan beads).

If the line in the Bt vs. $t$ plot (Figure 4) passes through the origin, biosorption is controlled by intraparticle diffusion and the binding sites exist with the adsorbate within the internal portion of the adsorbent. If the line does not pass through the origin, biosorption is controlled by surface diffusion, with major binding sites on the surface [28].

In all graphs in Figure 4, the line passes through the origin, confirming that diffusion is the dominant sorption process of the four materials tested. This demonstrates that all adsorbents tested have high affinity for the DO 2GL dye, which supports the supposition of chemisorption. These results also indicate the presence of strong dye-binding sites within the adsorbents.
Using the second mathematical model proposed by Boyd et al. [27] (Equation (8)), it is possible to calculate the effective diffusion coefficient.

$$
D i=\frac{r^{2} \cdot B b}{\pi^{2}}
$$

in which $B b$ is calculated from the $B t$ graph as a function of $t, r$ is the average radius of the adsorbent particles and $D i$ is the effective diffusion coefficient $\left(\mathrm{cm}^{2} \mathrm{~s}^{-1}\right)$ of the DO $2 \mathrm{GL}$ dye in the adsorbents.

Di values (Table 2 ) obtained for the $S$. cerevisiae biomass indicate that only one external binding site of the adsorbent is interacting with the adsorbate [29]. With the chitosan beads, $D i$ values remained on the 
(a)

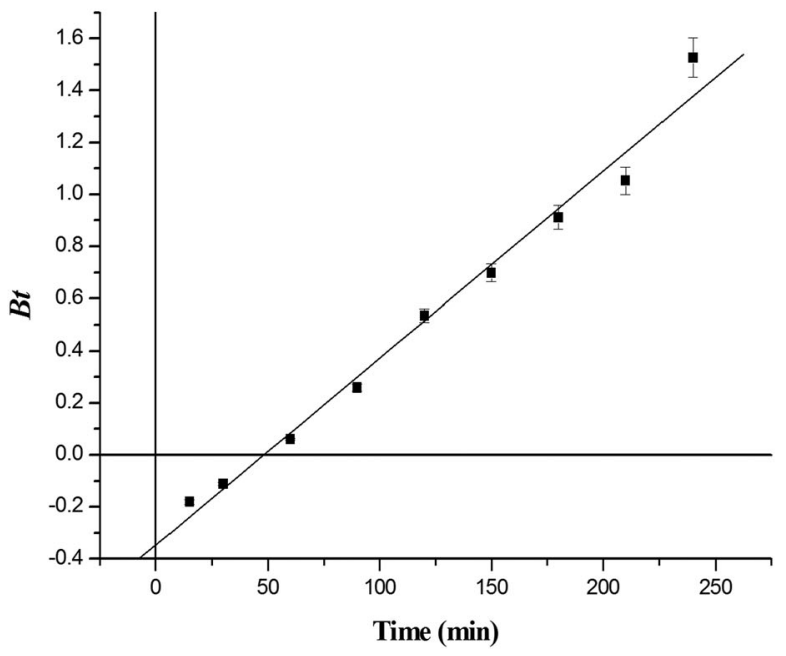

(c)

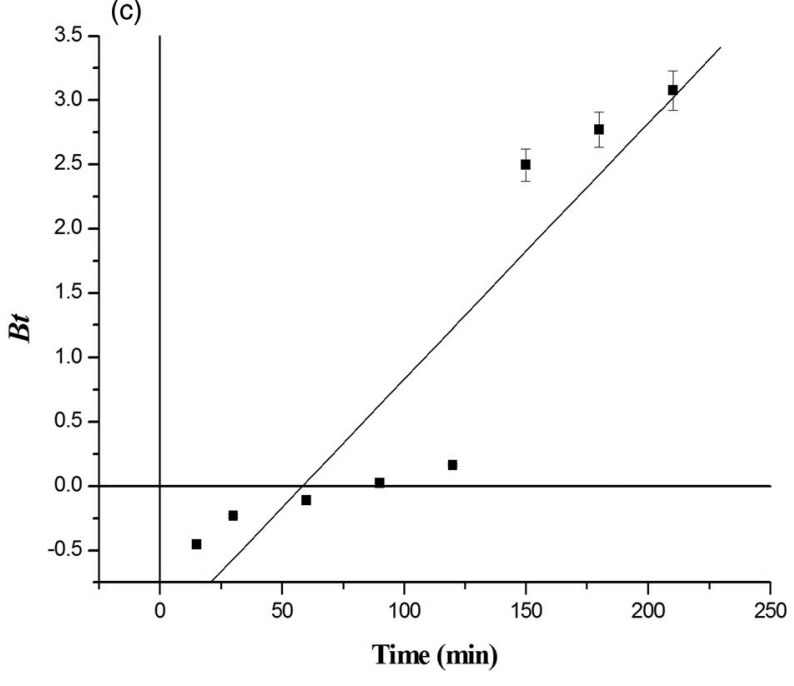

(b)

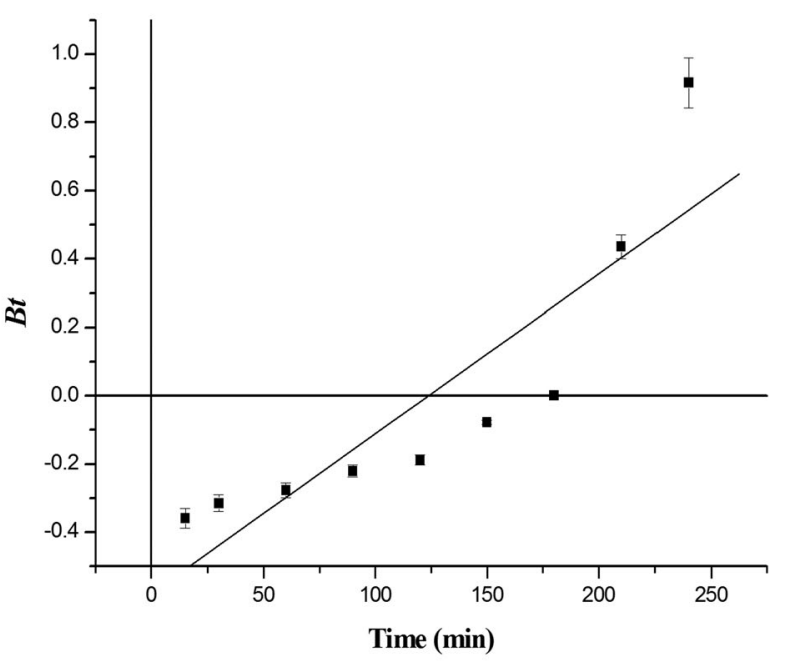

(d)

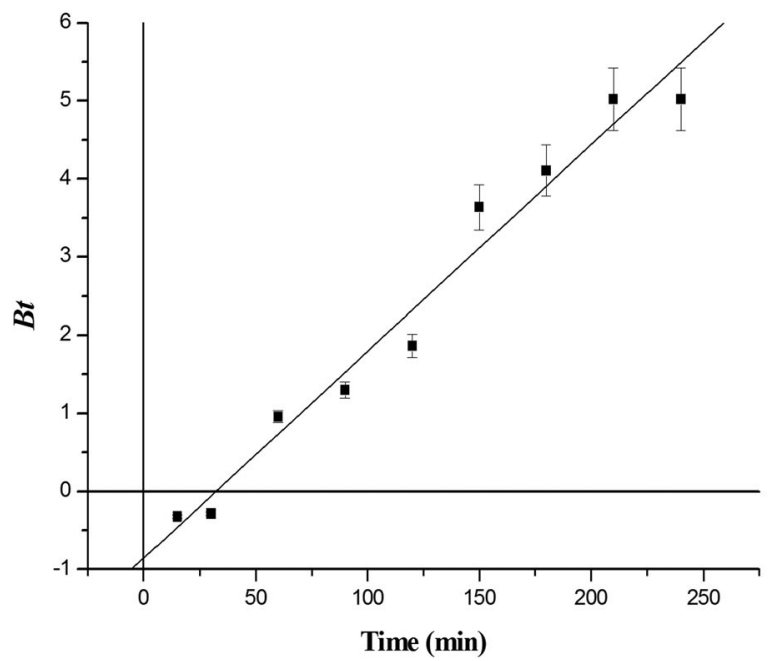

Figure 4. Boyd function plots ((a) S. cerevisiae biomass, (b) cross-linked chitosan beads, (c) ICC cross-linked chitosan beads and (d) ECM cross-linked chitosan beads).

order of $10^{-11} \mathrm{~cm}^{2} \mathrm{~s}^{-1}$, indicating that more than one external binding site is interacting with the adsorbate, which confirms the presence of heterogeneous interaction sites with the DO 2GL dye.

\subsection{Adsorption isotherms}

Isotherms are widely used to describe the relativity between biosorption capacity and equilibrium concentration at a constant temperature [30]. It is therefore possible to identify the sorption and desorption equilibrium at the solid/liquid interface and optimize the sorption process by varying $\mathrm{pH}$, agitation or other constants. It is also possible to classify the process as physical or chemical sorption. The Langmuir [31] and Freundlich [32] isotherms were used in the present study.
Table 2. Results of Boyd's models.

\begin{tabular}{lcclcc}
\hline & $R^{2}$ & SD & $r(\mathrm{~cm})$ & $B b\left(\mathrm{~s}^{-1}\right)$ & $D i\left(\mathrm{~cm}^{2} \mathrm{~s}^{-1}\right)$ \\
\hline $\begin{array}{c}\text { S. cerevisiae biomass } \\
\begin{array}{c}\text { Cross-linked chitosan } \\
\text { beads }\end{array}\end{array}$ & 0.991 & 0.108 & 0.00025 & 0.00718 & $4.546 \times 10^{-11}$ \\
$\begin{array}{c}\text { Cross-linked chitosan } \\
\text { beads (ICC) }\end{array}$ & 0.923 & 0.629 & 0.075 & 0.01991 & $1.134 \times 10^{-5}$ \\
$\begin{array}{c}\text { Cross-linked chitosan } \\
\text { beads (ECM) }\end{array}$ & 0.985 & 0.381 & 0.075 & 0.02645 & $1.507 \times 10^{-5}$ \\
\hline
\end{tabular}

The Langmuir isotherm (Equation (9)) is based on the assumption that the adsorption process occurs at specific homogeneous sites on the surface of the adsorbent and that, once a dye molecule occupies a site, no further adsorption can occur at that location, thereby forming monolayers [33].

$$
\frac{C e}{q e}=\frac{1}{b \cdot q m}+\frac{1}{q m} \cdot C e
$$


in which $q m$ is the maximum quantity of adsorbate adsorbed to the formed monolayer $\left(\mu \mathrm{g} \mathrm{mg}^{-1}\right)$ and $b$ is the Langmuir constant related to the affinity between the adsorbent and adsorbate $\left(\mathrm{mL} \mathrm{mg}^{-1}\right)$.

The equilibrium parameters are determined from the graph of angular coefficient (Ce/qe) vs. $\mathrm{Ce}$. The separation factor of the Langmuir isotherm was calculated using Equation (10), proposed by McKay et al. [34].

$$
R L=\frac{1}{1+b \cdot C_{o}}
$$

in which $R L$ is the separation factor in the Langmuir model. If $R L=1$, adsorption is linear. Thus, $R L=0$ means that adsorption is irreversible; $R L>1$ means that adsorption is unfavourable and $0<R L<1$ means that adsorption is favourable [34].

The Freundlich isotherm (Equation (11)) is based on the sorption of heterogeneous surfaces forming multiple layers [30]. More energetic sites are occupied primarily as the intensity of the interactions decreases with the progressive increase in the occupation of sorption sites [35].

$$
\ln q e=\ln k f+\frac{1}{n} \cdot \ln C e
$$

in which $k f$ is the Freundlich constant representing the solid adsorption capacity $\left(\mathrm{mL} \mathrm{mg}^{-1}\right)$ and $n$ is the adsorption constant intensity. By plotting the linear regression graph of Inqe vs. InCe, it is possible to determine the $n$ and $k f$ values.

All cross-linked chitosan beads fit the Freundlich model better, independently of the $\mathrm{pH}$ value, confirming interactions of heterogeneous sites and the formation of multiple layers. The $n$ values of the cross-linked chitosan beads (Table 3) at $\mathrm{pH} 2.50$ were greater than 1, demonstrating favourable adsorption with lateral interactions between adsorbate and adsorbent [36]. These results support the supposition of chemisorption. The $n$ values less than 1 obtained at $\mathrm{pH}$ values other than 2.50 (Table 3) are an indication of physisorption, which is adsorption with weaker interactions and, consequently, lower $q m$ and qe values.

The adsorption capacity of the solid $k f$ decreased with the increase in $\mathrm{pH}$ (Table 3), indicating less efficient adsorption as $\mathrm{pH}$ increases. Although this does not respect the Langmuir model, the $q m$ values obtained lend support to the supposition that $\mathrm{pH} 2.50$ is the best for adsorption.

The yeast biomass better fit the Langmuir model at $\mathrm{pH}$ 2.50 and 4.50 , indicating that a specific site is interacting with the adsorbate and forming monolayers. The constants $b$ and $q m$ were also higher at $\mathrm{pH} 2.50$ (Table 3), confirming that this specific site is interacting chemically with the adsorbate. At pH 6.50 and 8.50, the yeast biomass adhered to the Freundlich model, but demonstrated low $k f$ and $n$ values, indicating that a likely physical adsorption rather than a chemical interaction. The data obtained for $R L$ (Table 3) were lower at $\mathrm{pH} 2.50$ with all adsorbents, confirming more favourable adsorption at acid $\mathrm{pH}$ for all the materials tested.

Despite the uniqueness of the adsorbent materials tested in this paper, when comparing the values of qm obtained with other dye adsorption study data using similar adsorbent materials in the literature $[3,6,26,36]$, it is possible to see that the materials synthesized in this work did not reach adsorptive rates as large as those described in the respective studies,

\begin{tabular}{|c|c|c|c|c|c|c|c|c|c|}
\hline \multirow{2}{*}{$\frac{\text { S. cerevisiae biomass }}{\mathrm{pH}}$} & \multicolumn{5}{|c|}{ Langmuir isotherm } & \multicolumn{4}{|c|}{ Freundlich isotherm } \\
\hline & $q m$ & $b$ & $R L$ & $R^{2}$ & SD & $k f$ & $n$ & $R^{2}$ & SD \\
\hline 2.50 & 23.520 & 0.056 & 0.151 & 0.945 & 0.0286 & 0.00177 & 0.257 & 0.913 & 0.066 \\
\hline 4.50 & 0.924 & 0.010 & 0.500 & 0.975 & 0.529 & 0.0000003 & 0.118 & 0.964 & 0.501 \\
\hline 6.50 & 3.023 & 0.00582 & 0.632 & 0.924 & 0.443 & 0.000166 & 0.454 & 0.976 & 0.017 \\
\hline 8.50 & 0.908 & 0.015 & 0.400 & 0.962 & 0.709 & 14.549 & 0.447 & 0.979 & 0.020 \\
\hline Cross-linked chitosan beads & \multicolumn{5}{|c|}{ Langmuir isotherm } & \multicolumn{4}{|c|}{ Freundlich isotherm } \\
\hline the & $q m$ & $b$ & $R L$ & $R^{2}$ & SD & $k f$ & $n$ & $R^{2}$ & SD \\
\hline 2.50 & 31.037 & 0.0144 & 0.409 & 0.783 & 0.182 & 3.791 & 1.794 & 0.865 & 0.122 \\
\hline 4.50 & 0.982 & 0.00887 & 0.529 & 0.982 & 0.520 & 0.00810 & 0.182 & 0.985 & 0.128 \\
\hline 6.50 & 0.332 & 0.0102 & 0.495 & 0.791 & 2.741 & 0.00351 & 0.072 & 0.816 & 0.152 \\
\hline 8.50 & 1.708 & 0.0217 & 0.315 & 0.852 & 1.386 & 0.00465 & 0.0678 & 0.961 & 0.013 \\
\hline Cross-linked chitosan beads (ICC) & \multicolumn{5}{|c|}{ Langmuir isotherm } & \multicolumn{4}{|c|}{ Freundlich isotherm } \\
\hline $\mathrm{pH}$ & $q m$ & $b$ & $R L$ & $R^{2}$ & SD & $k f$ & $n$ & $R^{2}$ & SD \\
\hline 2.50 & 27.661 & 0.017 & 0.370 & 0.879 & 0.0862 & 7.158 & 2.264 & 0.952 & 0.097 \\
\hline 4.50 & 25.187 & 0.00573 & 0.635 & 0.825 & 0.148 & 0.0470 & 0.657 & 0.980 & 0.052 \\
\hline 6.50 & 24.746 & 0.00713 & 0.583 & 0.899 & 0.0164 & 0.00015 & 0.393 & 0.924 & 0.086 \\
\hline 8.50 & 2.715 & 0.00767 & 0.566 & 0.730 & 1.195 & 0.00000261 & 0.306 & 0.848 & 0.078 \\
\hline Cross-linked chitosan beads (ECM) & \multicolumn{5}{|c|}{ Langmuir isotherm } & \multicolumn{4}{|c|}{ Freundlich isotherm } \\
\hline $\mathrm{pH}$ & $q m$ & $b$ & $R L$ & $R^{2}$ & SD & $k f$ & $n$ & $R^{2}$ & SD \\
\hline 2.50 & 55.401 & 0.032 & 0.238 & 0.942 & 0.016 & 1.993 & 1.004 & 0.969 & 0.106 \\
\hline 4.50 & 1.506 & 0.00951 & 0.512 & 0.978 & 0.793 & 0.0000014 & 0.112 & 0.991 & 0.025 \\
\hline 6.50 & 0.767 & 0.0103 & 0.492 & 0.985 & 0.339 & $1.83 \times 10^{-7}$ & 0.090 & 0.991 & 0.039 \\
\hline 8.50 & 0.696 & 0.0092 & 0.521 & 0.945 & 1.163 & $1.54 \times 10^{-8}$ & 0.146 & 0.958 & 0.051 \\
\hline
\end{tabular}

Table 3. Results of isotherm at different pH values. 
presenting a lower dye removal coefficient. We should take into consideration that each study used a different dye, then the values of $q m$ are already subject to variation in a comparison of values. Other variations that may influence the adsorption and consequently the values of $q m$ are: temperature, initial concentration of dye and $\mathrm{pH}$ of the solution, among others [16]. Therefore, all these factors must be taken into account when comparing the values of $q m$ obtained with other adsorptive studies.

An important detail of this work when compared to other studies described in the literature $[3,6,26,36]$ is that the agitation speed during all the adsorption processes did not exceed $40 \mathrm{rpm}$, because the speed of agitation chosen in this study was thought to be the closest to an industrial scale effluent treatment, since the agitation of the holding tanks is very limited, with their propellers reaching speeds of $40-70 \mathrm{rpm}$. Agitation is a variable that can interfere with the adsorption process, and the higher the speed, the more contact with the adsorbate and hence the more efficient the dye removal process will occur [7]. Thus, the lower values of $q m$ obtained in this work, when compared to other studies, it is not a negative factor that disqualifies the proposed materials, since they were evaluated on certain different conditions. Nevertheless, these singular differences the ECM cross-linked chitosan beads presented a very close $q m$ values with other adsorbent materials already used and described in the literature $[16,28,37]$.

The ECM cross-linked chitosan beads had the highest adsorptive capacity (qe) at $\mathrm{pH} 2.50$ (Figure 5) and adsorption efficiency decreased with the increase in the $\mathrm{pH}$ of the medium. This same phenomenon was found for the S. cerevisiae biomass. However, ICC cross-linked chitosan beads had the highest sorption rate at alkaline $\mathrm{pH}$. Although the dye removal rate reduced with the increases in $\mathrm{pH}$, this material was still able to maintain higher values than the other materials. Thus, the $\mathrm{pH}$ of the medium exerts a direct influence on adsorption, but this influence varies depending on the adsorbent. The chitosan cross-linked beads demonstrated no significant change as the $\mathrm{pH}$ increased, maintaining similar sorption values (Figure 5), but adsorption capacity was much lower when compared to the ECM and ICC crosslinked chitosan beads, which confirms the increase in adsorptive capacity when cell immobilization is performed.

Thermodynamic studies help us understand the nature of adsorption by analysing changes in Gibbs free energy $(\Delta G)$, entropy $(\Delta S)$ and enthalpy $(\Delta H)$ [38]. Equation (12) is used to calculate the thermodynamic parameters used in the mathematical model proposed by van't Hoff.

$$
\ln \frac{q e}{C e}=\frac{\Delta S}{R g}-\frac{\Delta H}{R g} \cdot \frac{1}{T}
$$

in which $\mathrm{qe} / \mathrm{Ce}$ is the equilibrium constant obtained during temperature variation $\left(\mathrm{mol} \mathrm{g}^{-1}\right), T$ is the temperature $(\mathrm{K})$ and $R g$ is the universal gas constant (8.314 $\mathrm{J} \mathrm{mol}^{-1} \mathrm{~K}^{-1}$ ).

On a graph of In $q e / C e$ vs. $(1 / T)$, a line through the slope and intercept allows the calculation of entropy and enthalpy, with these values, Gibbs free energy is calculated using Equation (13).

$$
\Delta G=\Delta H-(\Delta S \cdot T)
$$

The positive enthalpy values (Table 4) demonstrate that adsorption is an endothermic process for the four adsorbents tested. The ECM cross-linked chitosan beads had enthalpy higher than $40 \mathrm{~kJ} \mathrm{~mol}^{-1}$, confirming a strong chemical interaction between these beads and the DO $2 \mathrm{GL}$ dye, which is likely an interaction by exchange or electron sharing. This strong adsorbate/adsorbent interaction may explain why the ECM cross-linked chitosan beads had the highest sorption capacity when compared to the other adsorbents studied.

Positive entropy values (Table 4) indicate connections and interactions at heterogeneous sites, with a decrease in binding energy as these sites are occupied, which is consistent with the results obtained with the Freundlich isotherms. Although this respects the Langmuir model as having specific dye-binding sites, it is natural for this phenomenon to occur in yeast cells due to the heterogeneity of the cell wall. Therefore, entropy values tend to be positive in the $S$. cerevisiae biomass [39]. These results also indicate that the association of the adsorbate at the solid-liquid interface becomes more random for all adsorbents [38].

Moreover, Gibbs free energy values decreased for all adsorbents as the temperature increased (Table 4). This demonstrates that adsorption is influenced by temperature, with an increase in sorption efficiency with the increase in temperature. These results also prove that the adsorption of DO $2 \mathrm{GL}$ dye is a spontaneous reaction for all adsorbents.

The values of Gibbs free energy obtained in this study proved to be negative in some stages for all adsorbents, which is a common result in adsorptive processes where there is a strong chemical interaction adsorbate/ adsorbent $[28,38]$. Since the Gibbs free energy measures the maximum work for a reaction process, we were able to indicate whether a reaction occurs naturally with a significant release of energy if its value is negative, hence favouring the reaction towards the products formed. Depending on the adsorbent and the adsorbate, the 

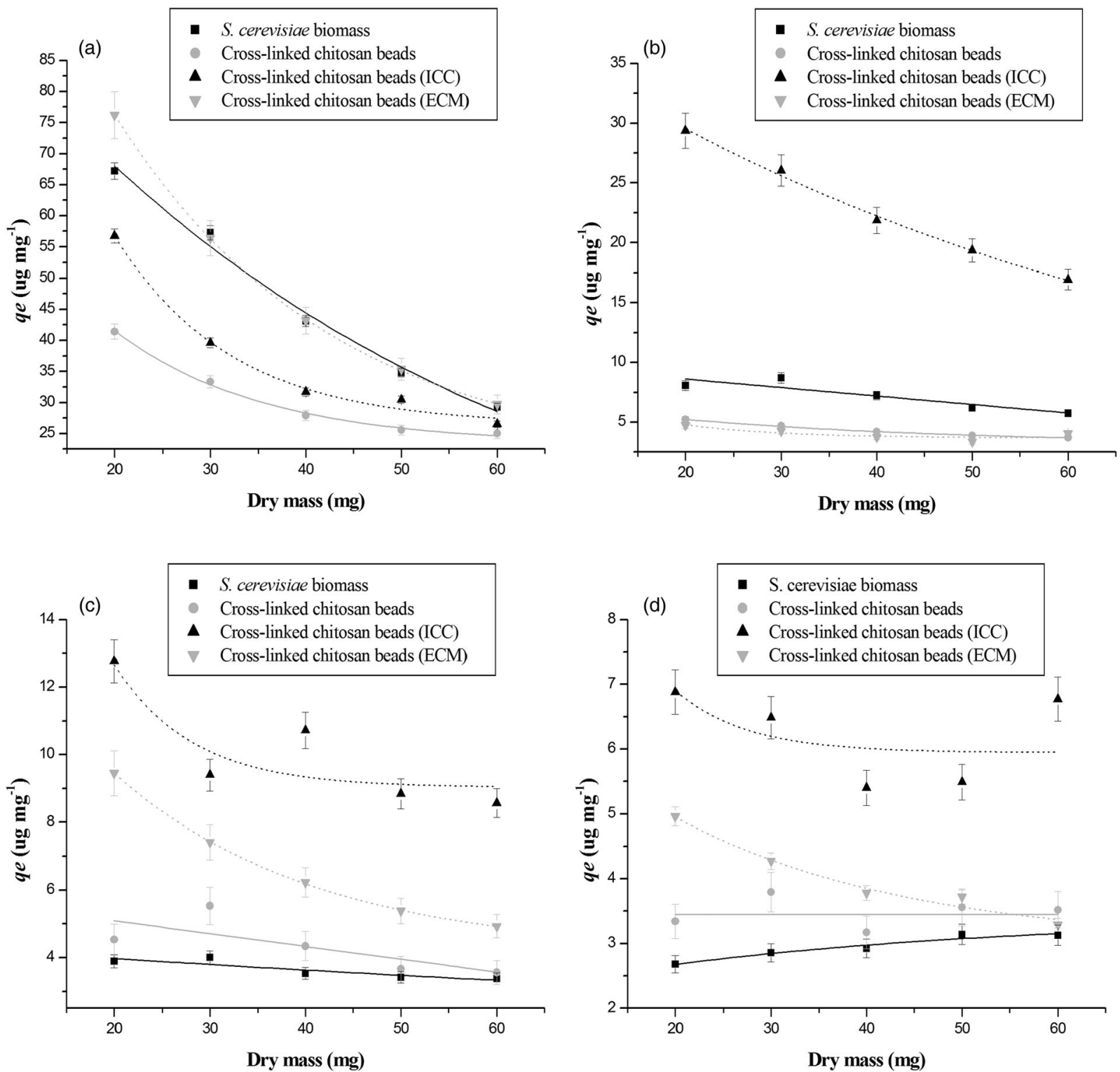

Figure 5. Graphs of adsorption varying pH of dye solution ((a) $\mathrm{pH} 2.50$, (b) $\mathrm{pH} \mathrm{4.50,} \mathrm{(c)} \mathrm{pH} 6.50$ and (d) $\mathrm{pH} 8.50$ ).

Table 4. Values obtained from the thermodynamic analysis.

\begin{tabular}{|c|c|c|c|c|c|c|}
\hline & & & & & & \\
\hline & $\Delta S\left(\mathrm{~kJ} \mathrm{~mol}^{-1} \mathrm{~K}^{-1}\right)$ & $\Delta H\left(\mathrm{~kJ} \mathrm{~mol}^{-1}\right)$ & $283.15 \mathrm{~K}$ & $293.15 \mathrm{~K}$ & $303.15 \mathrm{~K}$ & $323.15 \mathrm{~K}$ \\
\hline S. cerevisiae biomass & 0.027 & 5.672 & -1.973 & -2.243 & -2.513 & -3.053 \\
\hline Cross-linked chitosan beads & 0.065 & 20.618 & 2.213 & 1.563 & 0.913 & -0.386 \\
\hline Cross-linked chitosan beads (ICC) & 0.082 & 24.911 & 1.692 & 0.872 & 0.052 & -1.587 \\
\hline Cross-linked chitosan beads (ECM) & 0.146 & 43.211 & 1.871 & 0.411 & -1.048 & -3.968 \\
\hline
\end{tabular}

Gibbs free energy values may be positive, and may also present spontaneity reaction besides a strong chemical interaction [39]. However, this positive value indicates a reactive favouring for the reagents, revealing that it is easier to separate this adsorbate from the adsorbent.

In this case, these negative values corroborate the strong reactional interaction of the adsorption of the materials used in the present work, besides showing that their separation after the adsorption process will be an unfavourable system.

\subsection{FT-IR spectrophotometry}

FT-IR spectra are like fingerprints of molecules, as changes occur when the chemical structure has changed due to a connection or interaction with 
another molecule. FT-IR spectrophotometry can characterize such changes as well as identify the main binding sites. Thus, FT-IR is a useful tool for identifying possible adsorptions links and confirming whether adsorption occurs through a chemical or physical process [40]. Figure 6 shows the FT-IR spectrophotometric characterization of the dye and adsorbent materials.

The dye exhibited an intense peak at $1462 \mathrm{~cm}^{-1}$. This represents the stretching of the azo bond $-\mathrm{N}=\mathrm{N}-$, which is one of the main chemical groups in dyes. Another intense peak was found in the $1122-1195 \mathrm{~cm}^{-1}$ region, these bands represent carbon vibration in aromatic rings. Peaks 1038 and $622 \mathrm{~cm}^{-1}$ represent the vibration and stretching of sulphonic groups in the dye. The $567 \mathrm{~cm}^{-1}$ band is the vibration of $-\mathrm{C}-\mathrm{NH}_{2}$. The band at $1632 \mathrm{~cm}^{-1}$ is the deformation of the $-\mathrm{C}-\mathrm{O}$ band and the small peak at $850 \mathrm{~cm}^{-1}$ represents the deformation of the $-\mathrm{C}-\mathrm{H}$ bonds in aromatic rings. Peaks 2359 and $3433 \mathrm{~cm}^{-1}$ are carbon residues and primary amines, which were identified during sample reading. All peaks form a well-defined characterization of the DO 2GL chemical dye molecule (Figure 7).

The spectra of the $S$. cerevisiae cell (Figure 6) exhibited two intense peaks in regions 1650 and $1540 \mathrm{~cm}^{-1}$, which are vibrations of the binding of the amide group $\mathrm{R}-\mathrm{NH}-$ $\mathrm{C}-\mathrm{O}-\mathrm{CH}_{3}$ in the chitin of the yeast cell wall. These peaks may also be attributed to sugars present in the cell wall and membrane. The $1350 \mathrm{~cm}^{-1}$ region is the elongation of the $-\mathrm{C}-\mathrm{NH}$ bond, which probably also belongs to the chitin of the cell wall. Another intense peak is in the $1040 \mathrm{~cm}^{-1}$ region, which represents vibrations of $-\mathrm{C}-\mathrm{O}$ bonds. The $1234 \mathrm{~cm}^{-1}$ band shows the vibration of C9O bonds, which is another chemical group in chitin as well as several other molecules of the yeast cell wall structure. The $596 \mathrm{~cm}^{-1}$ band is the $-\mathrm{C}-\mathrm{N}-\mathrm{C}$ stretching in S. cerevisiae cell proteins. The peaks in regions 3381 and $2924 \mathrm{~cm}^{-1}$ represent bonding vibrations of the chemical groups $-\mathrm{OH}$ and $-\mathrm{CH}_{2}-\mathrm{CH}_{3}$, which are present in the chemical structure of the yeast cell molecules.

The cross-linked chitosan beads (Figure 6) exhibited an intense peak in the $1076 \mathrm{~cm}^{-1}$ region, representing vibrations of the $-\mathrm{C}-\mathrm{O}$ bond. The $1152 \mathrm{~cm}^{-1}$ band represents the stretching of the $-\mathrm{CH}-$ cyclic linkage, which is a common chemical group among the monomers of the biopolymer (Figure 8). Other intense peaks are found at 1650 and $1377 \mathrm{~cm}^{-1}$, which represent the vibration and stretching of $-\mathrm{CH}-\mathrm{NH}_{2}$ binding, these being the major functional groups of chitosan binding [41]. The peak at $603 \mathrm{~cm}^{-1}$ constitutes the vibration of the $-\mathrm{CH}-\mathrm{OH}$ bond, which is another common bond in the monomers of the biopolymer. The band $2867 \mathrm{~cm}^{-1}$ represents $-\mathrm{OH}$ bonding vibrations. The 3433 and
$2360 \mathrm{~cm}^{-1}$ bands represent primary amines and carbon residues that remained present during the analysis.

The FT-IR spectrum of the ICC cross-linked chitosan beads (Figure 6) exhibited similar bands to those of the S. cerevisiae and the cross-linked chitosan beads, with identical peaks at 3381 and $1377 \mathrm{~cm}^{-1}$. Other peaks, although not in the same region, represent vibrations similar to other spectra, as in the case of peaks 1632 and $1304 \mathrm{~cm}^{-1}$, representing vibrations of the $-\mathrm{CH}-$ $\mathrm{NH}_{2}$ and $-\mathrm{C}-\mathrm{O}$ bonds. However, as these peaks are in different locations and do not present the same shape of the spectrum, it can be said that these are connections at different points of the molecule [42]. Band $1084 \mathrm{~cm}^{-1}$ represents $-\mathrm{CH}-\mathrm{OH}$ bonds. Although this is a common group in chitosan, this band only appeared in ICC cross-linked chitosan beads. The $564 \mathrm{~cm}^{-1}$ band is the vibration of typical $-\mathrm{R}-\mathrm{N}-\mathrm{C}$ groups of proteins. Peak $1513 \mathrm{~cm}^{-1}$ is attributed to sugars from the wall and yeast cell membrane. Peak $2933 \mathrm{~cm}^{-1}$ represents vibrations of $-\mathrm{CH}_{2}-\mathrm{CH}_{3}$ bonds. Through these singularities and similarities with the other two spectra, one may state that the cells were successfully immobilized by contact on the chitosan beads [41].

The FT-IR spectrum (Figure 6) of the ECM cross-linked chitosan beads exhibited very different bands from the other spectra, but some similarities were still present For instance, peaks 1076 and $1650 \mathrm{~cm}^{-1}$ are identical to the spectrum of cross-linked chitosan beads. The band in the $2924 \mathrm{~cm}^{-1}$ region is also similar to that found in the yeast spectrum. A prominent band is found in region $1550 \mathrm{~cm}^{-1}$, which represents the binding of the amide group $\mathrm{R}-\mathrm{NH}-\mathrm{C}-\mathrm{O}-\mathrm{CH}_{3}$ probably belonging to the yeast chitin. The peak found at $649 \mathrm{~cm}^{-1}$ is the stretching of the $-\mathrm{R}-\mathrm{PO}_{3}-\mathrm{OH}$ bond present in the sodium tripolyphosphate crosslinking matrix. Another unique band is found at $1404 \mathrm{~cm}^{-1}$, which is the vibration of a protonation region $-\mathrm{CH}-\mathrm{NH}_{3}^{+}$that occurs due to the complexation of chitosan with sodium tripolyphosphate (Figure 9).

The FT-IR spectra of the ICC cross-linked chitosan beads observed after adsorption at acidic and alkaline $\mathrm{pH}$ (Figure 10) revealed that physical adsorption took place in both cases, as no change occurred in the FT-IR spectra [40]. The kinetic and thermodynamic studies indicated the possible occurrence of chemisorption due to the different points of connection with the dye, considering the presence of both sites of the crosslinked chitosan and those of the immobilized yeast cells. This can cause exponential adsorption, with the occurrence of high sorption synergy with the dye, even without a strong adsorbate/adsorbent interaction, consequently presenting results similar to chemisorption. 

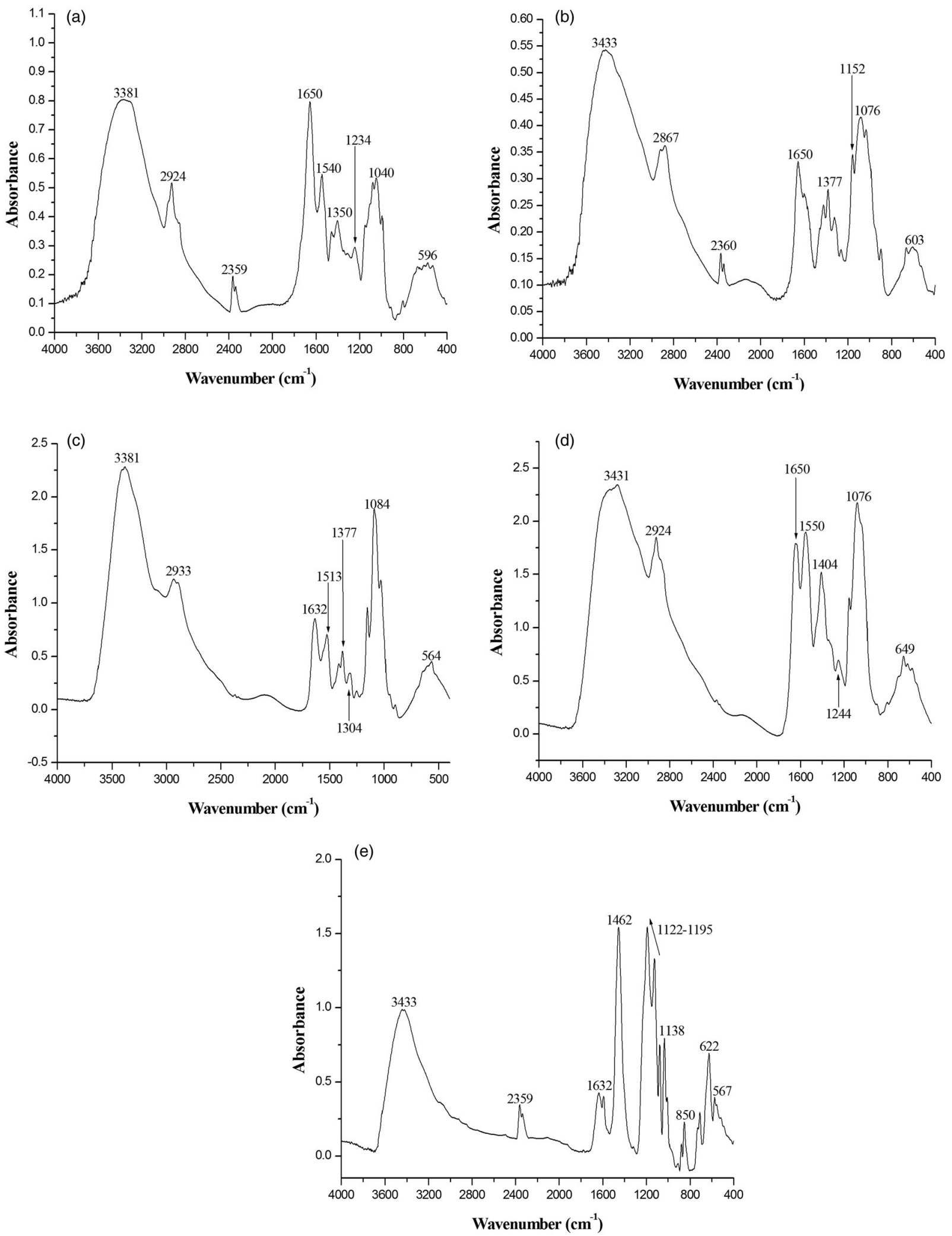

Figure 6. Characterization of DO 2GL dye and adsorbents by FT-IR spectrophotometry ((a) S. cerevisiae biomass, (b) cross-linked chitosan beads, (c) ICC cross-linked chitosan beads, (d) ECM cross-linked chitosan beads and (e) DO 2GL dye).

The Freundlich isotherm proved to be the better model for the ICC cross-linked chitosan beads, since this model describes physical adsorption well. The higher intensity of the bands after adsorption at acid $\mathrm{pH}$ likely occurred due to the protonation of the medium, enabling the formation of hydrogen bonds 


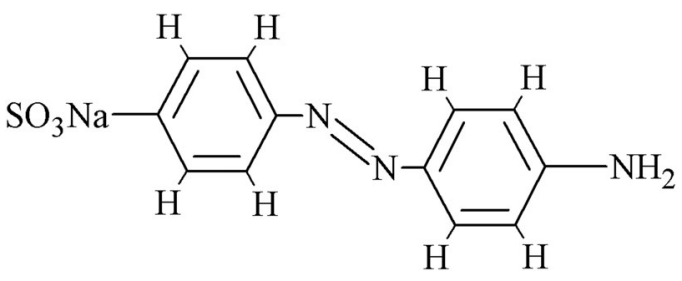

Figure 7. Chemical structure of Direct Orange 2GL dye.

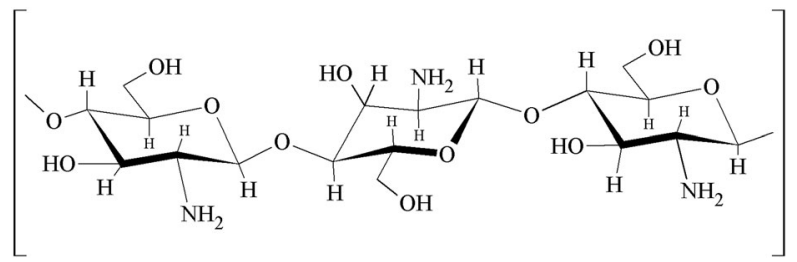

Figure 8. Chemical structure of chitosan.

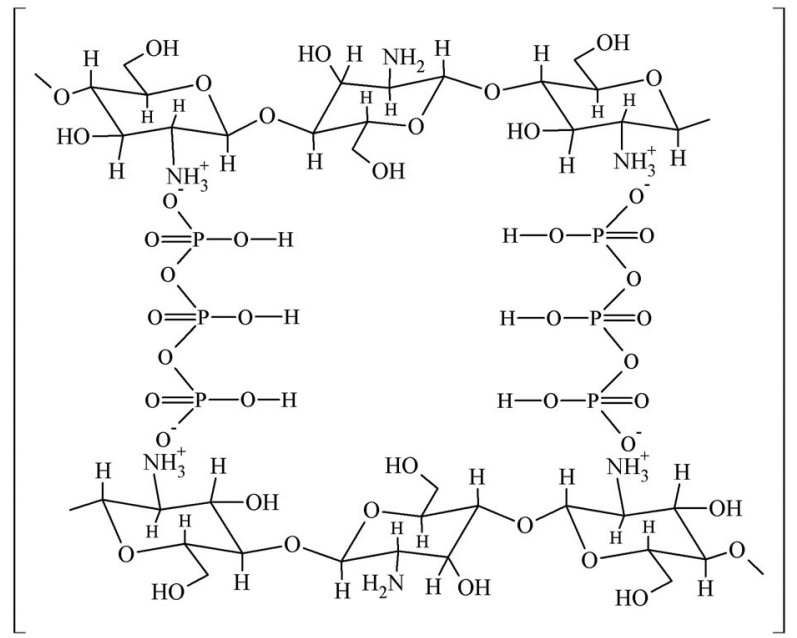

Figure 9. Structure of complex matrix of ECM cross-linked chitosan beads.

and increasing sorption efficiency. This probably does not occur when the $\mathrm{pH}$ is alkaline due to the weaker bonds, such as van der Waals forces [39]. However, the several sites of physical interactions allowed the ICC cross-linked chitosan beads to obtain the highest adsorption values at alkaline $\mathrm{pH}$ among the different materials.

The cross-linked chitosan beads also exhibited no changes in their FT-IR spectra (Figure 10), with identical bands even after adsorption at the two different $\mathrm{pH}$ values, also characterizing physisorption and confirming the fit to the Freundlich isotherm. At pH 8.50, however, a little noise and a slight deformation were found at 1563 and $1258 \mathrm{~cm}^{-1}$, which represent $-\mathrm{CH}-\mathrm{NH}_{2}$ and $-\mathrm{CH}-\mathrm{O}$ bonds vibrations that are common chemical groups in the chitosan molecule. These aspects do not alter the spectrum characteristic and indicate no change in the initial molecule or different chemical interaction [40]. The bands also exhibited higher intensity at $\mathrm{pH} 2.50$ than $\mathrm{pH} 8.50$, indicating greater affinity with the dye at acidic $\mathrm{pH}$, probably also due to $\mathrm{H}^{+}$ions in the solution, leading to an increase in adsorbate/adsorbent interactions.

The $S$. cerevisiae biomass spectra (Figure 10) exhibited small changes at 1350, 1234 and $805 \mathrm{~cm}^{-1}$, which constitute reductions in intensity and slight deformations that are not characterized as a change in the molecule [42]. However, the 1145 and $1024 \mathrm{~cm}^{-1}$ regions are clear changes in the spectra after adsorption at $\mathrm{pH} 2.50$. These peaks are stretches of $-\mathrm{C}=\mathrm{C}-$ bonds in aromatic rings and vibrations of groups $-\mathrm{SO}_{3}^{-}$, which belong to the DO $2 \mathrm{GL}$ dye. The peak at $955 \mathrm{~cm}^{-1}$ is characteristic of sugars present in yeast cell walls, which must be chemically interacting with the dye. The peak at $608 \mathrm{~cm}^{-1}$ represents vibrations of $-\mathrm{CH}-\mathrm{NH}-$ and $-\mathrm{CH}-$ $\mathrm{NH}_{2}-$, which are amine groups of the yeast that must be protonated at acidic $\mathrm{pH}$, possibly constituting another site of interaction with the dye. The band in the $434 \mathrm{~cm}^{-1}$ region is the stretch of binding between molecules $-\mathrm{CH}-\mathrm{C}$ and $-\mathrm{C}-\mathrm{C}-\mathrm{C}$ belonging to the dye or some structure of the yeast cell. It can be stated that there is a strong chemical interaction between the S. cerevisiae biomass and the DO $2 \mathrm{GL}$ dye at acidic $\mathrm{pH}$, corroborating the data obtained with the isotherms. In contrast, the yeast spectra exhibited no changes after adsorption at $\mathrm{pH} 8.50$ (Figure 10), confirming that adsorption was a physical process, as indicated by the isotherm studies.

The FT-IR spectra of the ECM cross-linked chitosan beads after adsorption at $\mathrm{pH} 2.50$ (Figure 10) revealed bands that underwent slight deformations, such as the peaks at 1650, 1550 and $1076 \mathrm{~cm}^{-1}$. However, an analysis of the other peaks confirms the occurrence of chemisorption. The small deformation at $1712 \mathrm{~cm}^{-1}$ is the vibration of binding $=\mathrm{C}-\mathrm{C}$ in aromatic rings, likely belonging to the dye, which is an indication of its chemical interaction with the ECM cross-linked chitosan beads. The deformation in the $1086 \mathrm{~cm}^{-1}$ region is the C-N stretching of the amino group, indicating an interaction. The $1062 \mathrm{~cm}^{-1}$ band is characteristic of $\mathrm{b}(1 \rightarrow 3)$ glucans in the yeast cell walls, which is another likely binding site for the dye. Another peak with a distinct change is seen in the $1036 \mathrm{~cm}^{-1}$ region, which are the vibration of $-\mathrm{C}-\mathrm{O}$ groups in chitosan and the structure of the yeast cells. The 887,656 and $612 \mathrm{~cm}^{-1}$ bands exhibited very visible differences. These peaks represent the stretching of sulphonic groups, elongation of aromatic ring carbon bonds and the vibration of $-\mathrm{CH}-\mathrm{SO}_{3}^{-}$, all of which belong to the dye and are interacting by exchange or electron 

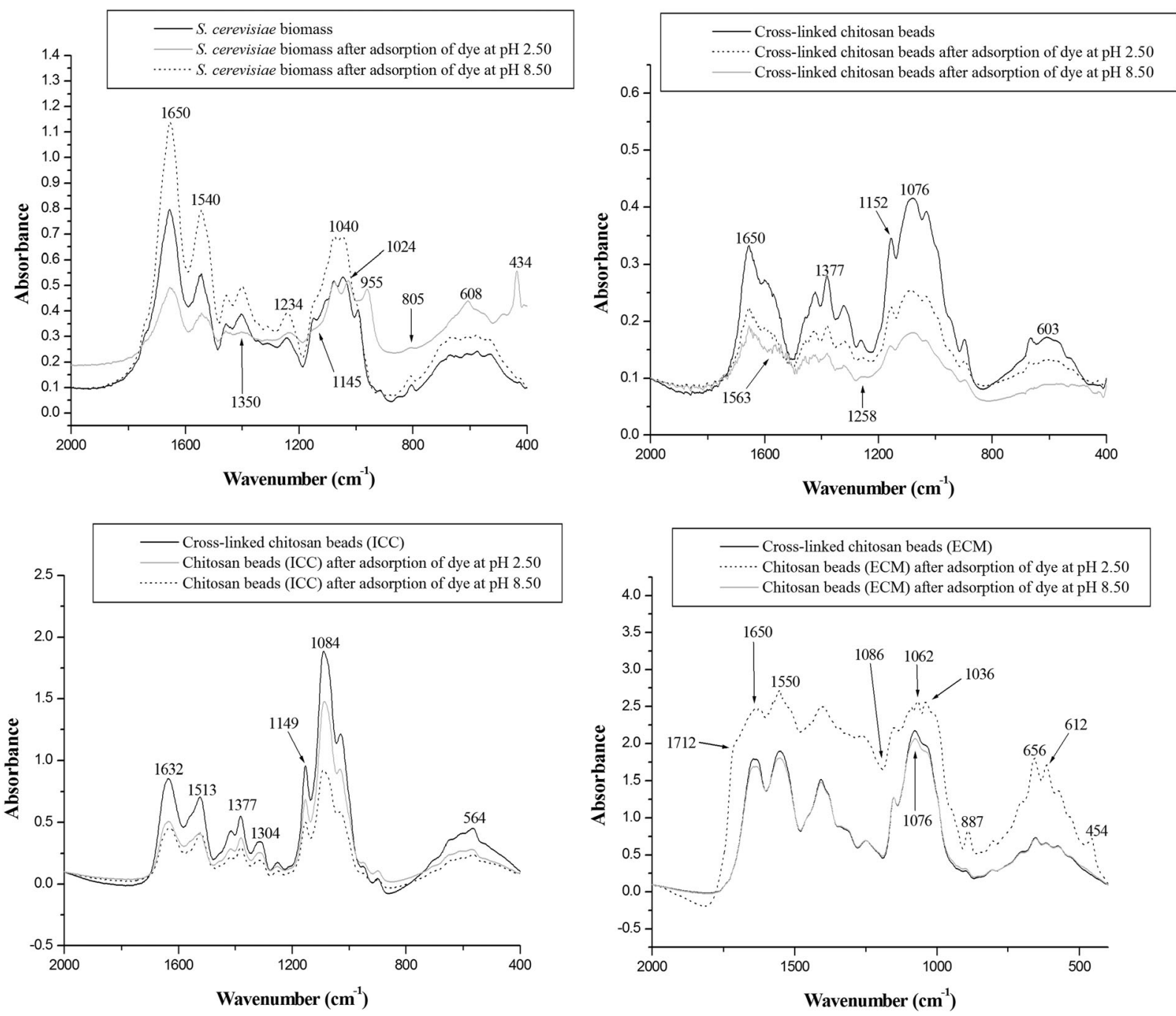

Figure 10. FT-IR spectrum of adsorbent materials before and after adsorption.

sharing with the ECM cross-linked chitosan beads. Another unique peak found in this spectrum is found in the $454 \mathrm{~cm}^{-1}$ region, which constitutes primary amine vibrations belonging to yeast proteins. These amines are also likely interacting chemically with the dye. These results confirm the higher adsorbate/adsorbent interaction with the ECM cross-linked chitosan beads and consequent greater adsorptive capacity at $\mathrm{pH}$ 2.50. The adsorption FT-IR spectrum of the ECM cross-linked chitosan beads at pH 8.50 (Figure 10) exhibited no changes, confirming the occurrence of physisorption. This result corroborates the results of the isotherm studies, in which the values of the Freundlich constants indicated this phenomenon at pH 4.50, 6.50 and 8.50.

\subsection{Toxicity test with microcrustacean $D$. similis}

The microcrustacean $D$. similis demonstrated considerable sensitivity to the DO $2 \mathrm{GL}$ dye, with $\mathrm{LC}_{100}$ and $\mathrm{LC}_{50}$ values of 1100 and $200 \mu \mathrm{g} \mathrm{mL}^{-1}$. The results comparison revealed that the yeast biomass and the cross-linked chitosan beads achieved a decrease in the toxicity of the dye in the solution (Table 5). Despite the lower microcrustacean mortality after dye removal, this reduction was not statistically relevant [20].

In contrast, a significant reduction in $D$. similis mortality was found with the ICC and ECM cross-linked chitosan beads. Using $500 \mathrm{mg}$ of these adsorbent materials, it was possible to remove more than half of the dye concentration from the solution, significantly reducing the mortality of the microcrustacean. This demonstrates the efficiency of these two materials in removing the toxicity of the dye solution after adsorption.

One of the probable reasons for the lack of significant results regarding the reduction in $D$. similis mortality with S. cerevisiae and the cross-linked chitosan beads was that the $\mathrm{pH}$ and temperature used in this test were not ideal, 
Table 5. Data from toxicity test with $D$. similis before and after adsorption.

\begin{tabular}{|c|c|c|c|c|}
\hline & $\begin{array}{c}\text { Initial dye } \\
\text { concentration } \\
\mathrm{LC}_{50}\left(\mu \mathrm{g} \mathrm{mL}^{-1}\right)\end{array}$ & $\begin{array}{c}\text { Final dye } \\
\text { concentration } \\
\left(\mu \mathrm{g} \mathrm{mL}^{-1}\right)\end{array}$ & $\begin{array}{c}\text { Mortality } \\
(\%)\end{array}$ & $\begin{array}{l}\text { Kruskal- } \\
\text { Wallis } \\
\text { (Dunn) }\end{array}$ \\
\hline $\begin{array}{l}\text { Control } \\
\text { S. cerevisiae } \\
\text { biomass }\end{array}$ & 200.00 & 200.00 & 50 & - \\
\hline $100 \mathrm{mg}$ & 200.00 & 188.28 & 45 & n.s. \\
\hline $250 \mathrm{mg}$ & 200.00 & 174.36 & 40 & n.s. \\
\hline $\begin{array}{l}500 \mathrm{mg} \\
\text { Cross-linked } \\
\text { chitosan } \\
\text { beads }\end{array}$ & 200.00 & 133.85 & 22.5 & n.s. \\
\hline $100 \mathrm{mg}$ & 200.00 & 190.82 & 47.5 & n.s. \\
\hline $250 \mathrm{mg}$ & 200.00 & 179.04 & 40 & n.s. \\
\hline $\begin{array}{l}500 \mathrm{mg} \\
\text { Cross-linked } \\
\text { chitosan } \\
\text { beads (ICC) }\end{array}$ & 200.00 & 151.20 & 30 & n.s. \\
\hline $100 \mathrm{mg}$ & 200.00 & 162.32 & 30 & n.s. \\
\hline $250 \mathrm{mg}$ & 200.00 & 111.63 & 15 & n.s. \\
\hline $500 \mathrm{mg}$ & 200.00 & 33.01 & 5 & $\begin{array}{c}p \text { value } \\
<.05\end{array}$ \\
\hline $\begin{array}{l}\text { Cross-linked } \\
\text { chitosan } \\
\text { beads } \\
\text { (ECM) }\end{array}$ & & & & \\
\hline $100 \mathrm{mg}$ & 200.00 & 180.05 & 45 & n.s. \\
\hline $250 \mathrm{mg}$ & 200.00 & 161.43 & 30 & n.s. \\
\hline $500 \mathrm{mg}$ & 200.00 & 98.91 & 12 & $\begin{array}{c}p \text { value } \\
<.05\end{array}$ \\
\hline
\end{tabular}

Note: n.s. not significant

which diminished the efficiency of these materials at adsorbing the dye. Since the reduction in microcrustacean mortality is proportional to the removal of the dye, an increase in the adsorbent mass of these two materials might lead to significant results in reducing the toxicity of solution. Nevertheless, the superior capacity of the ICC and ECM cross-linked chitosan beads in removing the dye and toxicity of the solution is highlighted.

To verify the applicability of the materials synthesized in this work, all the dye used or the residue that remained after its use was treated using the ICC and ECM crosslinked chitosan beads without discarding any residue after the tests. All the adsorbent material used in this treatment was placed in a single Eppendorf vial (Figure 11) to impede these residues from contributing to an effluent and concentrating its entire volume in a small area. Thus, rather than the dye being scattered and contaminating litres of water, it is trapped inside an Eppendorf vial, causing no further contamination.

In this paper, we did not do adsorption study with effluent continuous flow or reusing the adsorbent materials in multiple cycles of adsorption at where the material was used more than once in the same dye removal process. Although adsorbent reuse is important from an industrial scale effluent treatment perspective [43], in the case of ICC and ECM chitosan beads synthesized in this study

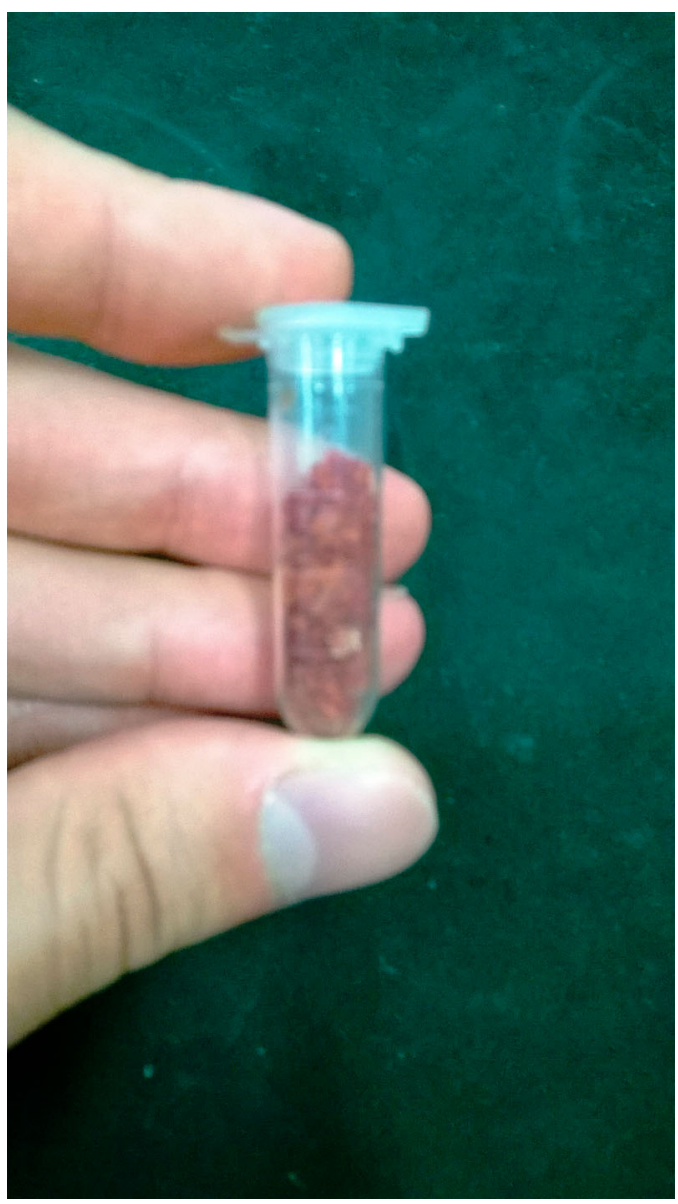

Figure 11. ICC and ECM cross-linked chitosan beads used to treat all dye residues produced in experiments.

they would not behave efficiently, as proven in kinetic studies they reach a point of adsorption saturation, not removing more molecules of the adsorbate after the reach of this rate, saturating its adsorptive capacity. Consequently, it is not recommended to reuse this material if this dye removal rate has reached this maximum value, because it will no longer remove the dye effectively, since all its sites of interaction with the adsorbate are already occupied [23].

\section{Conclusion}

The materials synthesized in this work exhibited similar characteristics and presented no defects that would disqualify their use, demonstrating that the techniques used for their synthesis are efficient. The immobilization techniques of yeasts by contact and encapsulation in the polymeric matrix of chitosan were shown to be effective, with cell immobilization confirmed by FT-IR spectrometry.

All the adsorbents respected the kinetic pseudosecond order model, but the occurrence of intraparticle diffusion was verified, which was the phenomenon 
controlling the sorption process with the four adsorbents tested.

All the cross-linked chitosan beads better fit the Freundlich isotherm, regardless of the $\mathrm{pH}$ of the dye solution. The $S$. cerevisiae biomass respected the Langmuir isotherm when the dye solution was at $\mathrm{pH} 2.50$ and 4.50, but better fit the Freundlich model at $\mathrm{pH} 6.50$ and 8.50. All adsorbents were influenced by the $\mathrm{pH}$ of the medium, with more alkaline $\mathrm{pH}$ causing less interaction between the dye and adsorbents and, consequently, less efficient adsorption.

The FT-IR spectrophotometric analyses confirmed that cell-free cross-linked chitosan beads and ICC cross-linked chitosan beads exhibited physisorption at both acid and alkaline $\mathrm{pH}$, but the ICC chitosan beads had several interaction sites with the DO 2GL dye, which explains its greater sorption capacity when compared to the cellfree cross-linked chitosan beads. The FT-IR spectrophotometric analyses also confirmed the occurrence of chemisorption at acid $\mathrm{pH}$ with the ECM cross-linked chitosan beads and $S$. cerevisiae biomass, but physisorption occurred with both materials at alkaline $\mathrm{pH}$.

The thermodynamic studies demonstrated that the adsorption of the four materials is influenced by temperature, with a higher temperature leading to more efficient sorption. The adsorption of the four materials was also an endothermic, spontaneous reaction.

Bioassays with $D$. similis confirmed the ability of ICC and ECM cross-linked chitosan beads to significantly remove toxicity from the dye solution, drastically reducing the mortality of microcrustacean. It can also be concluded that the immobilization of yeast cells on the ICC and ECM cross-linked chitosan beads was very important to increasing the adsorbent capacity of these materials. Thus, the present study demonstrates a novel, highly applicable material for the treatment of textile effluents that removes the staining and toxicity of the solution.

\section{Acknowledgements}

The authors acknowledge the thoughtful review by Dr Renato Nallin Montagnolli. The authors alone, of course, take responsibility for the final text and any errors that appear therein.

\section{Disclosure Statement}

No potential conflict of interest was reported by the authors.

\section{Funding}

This study received support from the Brazilian fostering agency Conselho Nacional de Desenvolvimento Científico e Tecnológico (CNPq) - process 130621/2016-1.

\section{ORCID}

Guilherme Dilarri (D) http://orcid.org/0000-0003-2625-7392

Carlos Renato Corso (D) http://orcid.org/0000-0002-8252-4419

\section{References}

[1] Lalnunhlimi S, Krishnaswamy V. Decolorization of azo dyes (Direct Blue 151 and Direct Red 31) by moderately alkaliphilic bacterial consortium. Braz J Microbiol. 2016;47:39-46.

[2] Toor AP, Verma A, Jotshi CK, et al. Photocatalytic degradation of direct yellow 12 dye using UV/TiO, in a shallow pond slurry reactor. Dyes Pigm. 2006;68:53-60.

[3] Farah JY, El-Gendy NS, Farahat LA. Biosorption of astrazone blue basic dye from an aqueous solution using dried biomass of Baker's yeast. J Hazard Mater. 2007;148:402-408.

[4] Raval NP, Shah PU, Shah NK. Adsorptive amputation of hazardous azo dye Congo red from wastewater: a critical review. Environ Sci Pollut Res. 2016;23:14810-14853.

[5] Wang $H$, Wang $Y$, Yan $H$. Binding of sodium dodecyl sulfate with linear and branched polyethyleneimines in aqueous solution at different $\mathrm{pH}$ values. Langmuir. 2006;22:1526-1533.

[6] Ngah WSW, Ariff NFM, Hanafiah MAKM. Preparation, characterization, and environmental application of crosslinked chitosan-coated bentonite for Tartrazine adsorption from aqueous solutions. Water Air Soil Pollut. 2010;206:225.

[7] Crini G, Badot PM. Application of chitosan, a natural aminopolysaccharide, for dye removal from aqueous solution by adsorption process using batch studies: a review of recent literature. Prog Polym Sci. 2008;33:399-447.

[8] Baraldi PT, Correa AG. Baker's yeast, Saccharomyces cerevisiae, as a tool for the synthesis of pheromones. Química Nova. 2004;27:421-431.

[9] Jadhav JP, Parshetti GK, Kalme SD, et al. Decolourization of azo dye methyl red by Saccharomyces cerevisiae MTCC 463. Chemosphere. 2007;68:394-400.

[10] Saifuddin N, Dinara S. Immobilization of Saccharomyces cerevisiae onto cross-linked chitosan coated with magnetic nanoparticles for adsorption of Uranium (VI) ions. Adv Nat Appl Sci. 2012;6:249-267.

[11] Vijayaraghavan K, Yun Y. Bacterial biosorbents and biosorption. Biotechnol Adv. 2008;26:266-291.

[12] Zhou LC, Li YF, Bai X. Use of microorganisms immobilized on composite polyurethane foam to remove $\mathrm{Cu}(\mathrm{II})$ from aqueous solution. J Hazard Mater. 2009;167:1106-1113.

[13] Toledo TV, Bellato CR, Souza CHF, et al. Preparation and evaluation of magnetic chitosan particles modified with ethylenediamine and $\mathrm{Fe}(\mathrm{III})$ for the removal of $\mathrm{Cr}(\mathrm{VI})$ from aqueous solutions. Química Nova. 2014;37:1610-1617.

[14] Dias FS, Queiroz DC, Nascimento RF, et al. Simple system for preparation of chitosan microspheres. Química Nova. 2008;31:160-163.

[15] Sumbu ZL, Thonart P, Bechet J. Action of patulin on a yeast. Appl Environ Microbiol. 1983;45:110-115.

[16] Sadaf S, Bhatti HN. Response surface methodology approach for optimization of adsorption process for the removal of Indosol Yellow BG dye from aqueous solution by agricultural waste. Desalin Water Treat. 2016;57:11773-11781. 
[17] Safa $Y$, Bhatti HN, Sultan $M$, et al. Synthesis, characterization and application of wheat bran/zinc aluminium and tea leaves waste/zinc aluminium biocomposites: kinetics and thermodynamics modeling. Desalin Water Treat. 2016;57:25532-25541.

[18] Corso CR, Almeida ACM. Bioremediation of dyes in textile effluents by Aspergillus oryzae. Microb. Ecol. 2009;57:384.

[19] Brazil - Ministry of the Environment, National Environment Council (CONAMA). Decree CONAMA $n^{\circ}$ 430, 2011.

[20] Moraes JR Jr, Bidoia ED. Colour degradation of simulated textile effluent by electrolytic treatment and ecotoxicological evaluation. Water Air Soil Pollut. 2015;226:286.

[21] Lagergren S. Zurtheorie der sogenannten adsorption gel osterstoffe. Kung-liga Svenska Vetenskapsakademiens, Handlingar. 1898;24:1-39.

[22] Ho YS, McKay G. Sorption of dye from aqueous solution by peat. Chem Eng J. 1998;70:115-124.

[23] Nandi BK, Goswami A, Purkait MK. Adsorption characteristics of brilliant green dye on kaolin. J Hazard Mater. 2009;161:387-395.

[24] Weber WJ, Morris JC. Kinetics of adsorption on carbon from solution. J Sanit Eng Div. 1963;89:31-60.

[25] Guerra DL, Airoldi C. The performance of urea-intercalated and delaminated kaolinites-adsorption kinetics involving cooper and lead. J Braz Chem Soc. 2009;20:19-30.

[26] Tanhaei B, Ayati A, Lahtinen M, et al. A magnetic mesoporous chitosan based core-shells biopolymer for anionic dye adsorption: kinetic and isothermal study and application of ANN. J Appl Polym Sci. 2016;133:43466.

[27] Boyd GE, Adamson AW, Myers LS. The exchange adsorption of ions from aqueous solution by organic zeolites, II. Kinetics. J Am Chem Soc. 1947;69:2836-2848.

[28] Aravindhan R, Rao JR, Nair BU. Removal of basic yellow dye from aqueous solution by sorption on green algae Caulerpa scalpelliformis. J Hazard Mater. 2007;142:68-76.

[29] Singh KP, Mohan D, Sinha S, et al. Color removal from wastewater using low-cost activated carbon derived from agricultural waste material. Ind Eng Chem Res. 2003;42:1965-1976.

[30] Wu Y, Jiang L, Wen Y, et al. Biosorption of Basic Violet 5BN and Basic Green by waste brewery's yeast from single and multicomponent systems. Environ Sci Pollut Res. 2012;19:510-521.

[31] Langmuir I. The adsorption of gases on plane surface of glass, mica and platinum. J. Am. Chem. Soc. 1918;40:1361-1403.
[32] Freundlich H. Adsorption in solution. Zeitschrift für Physikalische Chemie. 1906;40:1361-1368.

[33] Fat'hi MR, Asfaram A, Hadipour A, et al. Kinetics and thermodynamic studies for removal of acid blue 129 from aqueous solution by almond shell. J Environ Health Sci Eng. 2014;12:62.

[34] McKay G, Blair HS, Gardner JR. Adsorption of dyes on chitin: equilibrium studies. J Appl Polym Sci. 1982;27:3043-3057.

[35] Yousef Rl, El-Eswed B, Al-Muhtaseb AH. Adsorption characteristics of natural zeolites as solid adsorbents for phenol removal from aqueous solutions: kinetics, mechanism and thermodynamics studies. Chem Eng J. 2011;171:1143-1149.

[36] Annadurai G, Ling LY, Lee JF. Adsorption of reactive dye from an aqueous solution by chitosan: isotherm, kinetic and thermodynamic analysis. J Hazard Mater. 2008;152:337-346.

[37] Sadaf S, Bhatti HN, Nausheen S, et al. Application of a novel lignocellulosic biomaterial for the removal of Direct Yellow 50 dye from aqueous solution: batch and column study. J Taiwan Inst Chem Eng. 2015;47:160-170.

[38] Adane B, Siraj K, Meka N. Kinetic, equilibrium and thermodynamic study of 2-chlorophenol adsorption onto Ricinus communis pericarp activated carbon from aqueous solutions. Green Chem Lett Rev. 2015;8:1-12.

[39] Dilarri G, Almeida EJR, Pecora HB, et al. Removal of dye toxicity from an aqueous solution using an industrial strain of Saccharomyces cerevisiae (Meyen). Water Air Soil Pollut. 2016;227:317.

[40] Monash P, Pugazhenti G. Adsorption of crystal violet dye from aqueous solution using mesoporous materials synthesized at room temperature. Adsorption. 2009;15:390-405.

[41] Lawrie G, Keen I, Drew B, et al. Interactions between alginate and chitosan biopolymers characterized using FTIR and XPS. Biomacromolecules. 2007;8:2533-2541.

[42] Gao JF, Zhang Q, Su K, et al. Competitive biosorption of yellow $2 \mathrm{G}$ and reactive brilliant Red K-2G onto inactive aerobic granules: simultaneous determination of two dyes by first-order derivative spectrophotometry and isotherm studies. Bioresour Technol. 2010;101:5793-5801.

[43] Sadaf S, Bhatti HN, Arif M, et al. Adsorptive removal of direct dyes by PEl-treated peanut husk biomass: Box-Behnken experimental design. Chem Ecol. 2015;31:252-264. 